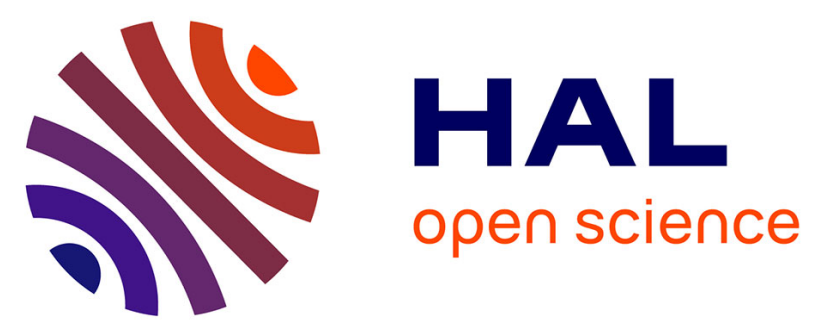

\title{
A genome scan of diversifying selection in Ophiocordyceps zombie-ant fungi suggests a role for enterotoxins in co-evolution and host specificity
}

Noppol Kobmoo, Duangdao Wichadakul, Nuntanat Arnamnart, Ricardo

Rodriguez de La Vega, Janet J Luangsa-Ard, Tatiana Giraud

\section{To cite this version:}

Noppol Kobmoo, Duangdao Wichadakul, Nuntanat Arnamnart, Ricardo Rodriguez de La Vega, Janet $\mathrm{J}$ Luangsa-Ard, et al.. A genome scan of diversifying selection in Ophiocordyceps zombie-ant fungi suggests a role for enterotoxins in co-evolution and host specificity. Molecular Ecology, 2018, 27 (18), pp.3582 - 3598. 10.1111/mec.14813 . hal-01921814

\section{HAL Id: hal-01921814 \\ https://hal.science/hal-01921814}

Submitted on 22 Nov 2018

HAL is a multi-disciplinary open access archive for the deposit and dissemination of scientific research documents, whether they are published or not. The documents may come from teaching and research institutions in France or abroad, or from public or private research centers.
L'archive ouverte pluridisciplinaire HAL, est destinée au dépôt et à la diffusion de documents scientifiques de niveau recherche, publiés ou non, émanant des établissements d'enseignement et de recherche français ou étrangers, des laboratoires publics ou privés. 
A genome scan of diversifying selection in Ophiocordyceps zombie-ant fungi suggests a role for enterotoxins in coevolution and host specificity

6 Noppol KOBMOO ${ }^{1,2}$, Duangdao WICHADAKUL ${ }^{3,4}$, Nuntanat ARNAMNART ${ }^{2}$, Ricardo C.

7 RODRÍGUEZ DE LA VEGA, Janet-Jennifer LUANGSA-ARD², Tatiana GIRAUD

$8{ }^{1}$ Ecologie Systématique Evolution, Univ. Paris-Sud, CNRS, AgroParisTech, Université Paris-Saclay 91400 Orsay,

9 France

$102^{2}$ National Center for Genetic Engineering and Biotechnology (BIOTEC), National Science and Development

11 Agency (NSTDA), 113 Thailand Science Park, Khlong Neung, Khong Luang, 12120 Pathum Thani, Thailand

$12{ }^{3}$ Chulalongkorn University Big Data Analytics and IoT Center (CUBIC), Department of Computer Engineering, 13 Faculty of Engineering, Chulalongkorn University, Payathai Rd., Wangmai, Pathumwan 10330, Bangkok Thailand

$14{ }^{4}$ Center of Excellence in Systems Biology, Faculty of Medicine, Chulalongkorn University, Payathai Rd., Wangmai,

15 Pathumwan 10330 Bangkok, Thailand

17 Corresponding author: Noppol Kobmoo,

18 E-mail: noppol.kob@biotec.or.th

20 Key words: Ophiocordyceps, host specificity, adaptation, positive selection, enterotoxins 


\section{Abstract}

23 Identification of the genes underlying adaptation sheds light on the biological functions targeted

24 by natural selection. Searches for footprints of positive selection, in the form of rapid amino-acid

25 substitutions, and the identification of species-specific genes have proved to be powerful

26 approaches to identifying the genes involved in host specialization in plant-pathogenic fungi. We

27 used an evolutionary comparative genomic approach to identify genes underlying host adaptation

28 in the ant-infecting genus Ophiocordyceps, which manipulates ant behavior. A comparison of the

29 predicted genes in the genomes of species from three species complexes - O. unilateralis, $O$.

30 australis and $O$. subramanianii - revealed an enrichment in pathogenesis-associated functions,

31 including heat-labile enterotoxins, among species-specific genes. Furthermore, these genes were

32 overrepresented among those displaying significant footprints of positive selection. Other

33 categories of genes suspected to be important for virulence and pathogenicity in entomopathogenic

34 fungi (e.g., chitinases, lipases, proteases, core secondary metabolism genes) were much less

35 represented, although a few candidate genes were found to evolve under positive selection. An

36 analysis including orthologs from other entomopathogenic fungi in a broader context showed that

37 positive selection on enterotoxins was specific to the ant-infecting genus Ophiocordyceps.

38 Together with previous studies reporting the overexpression of an enterotoxin during behavioral

39 manipulation in diseased ants, our findings suggest that heat-labile enterotoxins are important

40 effectors in host adaptation and coevolution in the Ophiocordyceps entomopathogenic fungi. 


\section{Introduction}

43 The identification of genes underlying adaptation is a major goal in evolutionary biology,

44 as it can shed light on the biological functions targeted by natural selection and the genetic

45 mechanisms generating new, adaptive variants. Innovation may be generated during evolution by

46 gene duplication followed by rapid amino-acid substitutions in one of the copies (Ohno 1970,

47 Zhang et al. 2002). Gene losses can also be adaptive (Juárez-Vázquez et al. 2017), particularly in

48 pathogens, as the absence of a molecule recognized by the host may enable the pathogen to colonize

49 its host without triggering a response from the host immune system (Albalat and Cañestro 2016;

50 Ghanbarnia et al. 2015, Rouxel and Balesdent 2017). Gene duplications and losses result in the

51 presence of species-specific genes, which are often over-represented among the genes involved in

52 adaptation (Gladieux et al. 2014, Lespinet et al. 2002; Zhou et al. 2015). Adaptation may also occur

53 through positive selection, with rapid amino-acid substitutions, typically detected as higher rates

54 of non-synonymous substitutions $\left(\mathrm{d}_{\mathrm{N}}\right)$ than of synonymous substitutions $\left(\mathrm{d}_{\mathrm{S}}\right)$ among orthologous

55 genes of closely related species (Kimura 1983; Ina 1996). Comparisons of $d_{N} / d_{S}$ ratios to neutral

56 expectations therefore also constitute a powerful approach to identifying genes under recurrent

57 positive selection (Yang and Nielsen 1998; Yang et al. 2000, Yang et al. 2005).

58 Pathogens are particularly interesting models for investigations of the genomic mechanisms

59 of adaptation, as they are locked in an arms race with their hosts, leading to continuous, rapid

60 evolution (Anderson et al. 2010; Kurtz et al. 2016). Identification of the genes underlying host-

61 specific adaptations in pathogens improves our fundamental understanding of natural selection and

62 evolution, but it also has more applied implications, shedding light on major epidemics and disease

63 emergence in plants and animals (Möller and Stukenbrock 2017). 
Fungi are the principal pathogens of plants (Anderson et al. 2004), and they also represent 65 threats to the health of many animals (Sexton and Howlett 2006; Fisher et al. 2012). Many studies 66 have searched for genes under positive selection as a means of identifying genes and functions 67 involved in the species-specific adaptation of fungal pathogens of plants (Aguileta et al. 2009; 68 Möller and Stukenbrock 2017). For example, in the Microbotryum and Botrytis fungal plant 69 pathogens, many such genes have been identified through comparative transcriptomics studies as

70 being under recurrent positive selection and they were involved in biological processes important

71 for the recognition and cell signaling between the host and the pathogen (Aguileta et al. 2010,

72 2012). More recently, next-generation sequencing made it possible to perform genome-wide scans

73 in plant -pathogenic fungi, resulting in the identification of an array of effectors under positive

74 selection (Badouin et al. 2017; Poppe et al. 2015; Schirmann et al. 2018; Stukenbrock et al. 2011;

75 Wicker et al. 2013) and species- or lineages-specific genes underlying adaptations (Baroncelli et 76 al. 2016, Hartmann et al. in press2018).

By contrast, far fewer such studies have been performed on entomopathogenic fungi (Wang and Wang 2017), despite the importance of identifying genes underlying host-specific adaptation

79 for the use of these fungi as biological control agents against insect pests in agriculture (Wang and

80 Feng 2014). Furthermore, an understanding of host-specificity and evolution in these insect

81 pathogens is of fundamental interest in its own right, particularly for fungi able to manipulate the

82 behavior of the insect host for their own benefit, as in the "zombie ant" phenomenon. Most genomic

83 studies on entomopathogenic fungi have focused on species with agricultural applications such as

84 Beauveria bassiana and Metarhizium anisopliae (Gao et al. 2011, Hu et al. 2014, Pattemore et al.

85 2014). However, these species have broad host ranges, and may not, therefore, be the best models

86 in which to study the genomics of host specialization and coevolution. Specialist Metarhizium 
87 strains and species generally have fewer genes, with notably fewer genes encoding host-killing

88 toxins (Wang et al. 2009), but more genes evolving under positive selection than generalists (Hu

89 et al. 2014). However, it remains unclear how adaptation has shaped the genomes of closely related

90 fungal entomopathogens specializing on different hosts.

91 We therefore tried to identify genes involved in host specificity in three complexes of

92 closely related species from the genus Ophiocordyceps (Hypocreales, Ascomycota): O. unilateralis

93 sensu lato, $O$. subramanianii s.l. and $O$. australis s. $l$. One of the key features of these pathogens

94 is their ability to manipulate their hosts to promote their own dispersal. Infected ants, often

95 described as "zombie ants", leave their nests and develop erratic behavior, wandering alone into

96 vegetation and then biting into a leaf located at a precise height and orientation optimal for

97 subsequent fungal dispersal just before they die. Fungal spores produced from the diseased ant are

98 thus dispersed farther, from a height (Hughes et al. 2011; Pontoppidan et al. 2009; De Bekker et

99 al. 2017; Hughes et al. 2016). Ophiocordyceps unilateralis s.l. is a highly diverse complex of

100 pathogenic cryptic species specific to formicine ants. It is distributed worldwide and many species

101 occur together in sympatry while displaying strong host specificity (Araùjo et al. 2017, Evans et

102 al. 2011; Kobmoo et al. 2012, 2015). Ants develop erratic behavior only when infected with their

103 specific pathogen species (De Bekker et al. 2014, Sakolrak et al. 2018). The taxonomy and

104 phylogeny of the other ant-manipulating Ophiocordyceps species complexes have been studied in

105 less detail, but host specificity is also considered to be the rule for these other taxa (Araujo et al.

106 2017).

107

We conducted a comparative genomic study of ant-infecting Ophiocordyceps species, with

108 the aim of identifying genes underlying host specificity by searching for species-specific genes and

109 genes evolving under positive selection. We sequenced the genomes of two closely related species 
110 of the O. unilateralis complex from Thailand: O. camponoti-leonardi and O. camponoti-saundersi,

111 specific to the ants Camponotus leonardi and C. saundersi, respectively. We also improved the

112 available genome assembly of another species of this complex, $O$. polyrhachis-furcata, specific to

113 Polyrhachis furcata (Wichadakul et al. 2015), and used the published genomes of other ant-

114 infecting Ophiocordyceps species (De Bekker et al. 2017): one genome of each of two species of

115 O. unilateralis s.l., O. kimflemingiae from the US infecting C. castaneus (Araujo et al. 2017; de

116 Bekker et al. 2015) and O. camponoti-rufipedis from Brazil specific to C. rufipes (Araujo et al.

117 2017; Evans et al. 2011); one genome of O. subramanianii s.l. from a ponerine ant in Ghana; one

118 genome of each of two strains of $O$. australis s.l. found on different ponerine ant species, from

119 Ghana and Brazil, probably belonging to different cryptic species (De Bekker et al. 2017).

120 The entomopathogenic fungi of the order Hypocreales are known to infect their host by

121 penetrating the cuticle (Boomsma et al. 2014). This process requires an array of proteinases, lipases

122 and chitinases. The acquisition of nutrients from the host requires proteases and glycoside

123 hydrolases, including trehalases in particular, as trehalose is a major carbon source present in the

124 insect hemolymph (Thompson 2003). Secondary metabolites, including toxins, help to combat the

125 host immune system and eventually kill the insect (Ortiz-Urquiza et al. 2010; Schrank and

126 Vainstein 2010). Ophiocordyceps polyrhachis-furcata has a more extensive family of genes

127 encoding putative heat-labile enterotoxins than other specialist entomopathogenic fungi

128 (Wichadakul et al. 2015), and some of these genes are expressed during host-specific behavioral

129 manipulation. Heat-labile enterotoxins may, therefore, act as neuromodulators (de Bekker et al.

130 2015). We hypothesized that enterotoxin-coding genes would be under recurrent positive selection

131 in ant-manipulating Ophiocordyceps fungi, as they have probably been involved in coevolution

132 with the host and in host-specific adaptation. Small proteins secreted by fungal pathogens are often 
133 involved in interactions with the host (Barrett and Heil 2012; Rafiqi et al. 2012). We therefore

134 conducted genome scans for positive selection and focused on the heat-labile enterotoxin gene

135 family and small secreted proteins. We conducted formal tests for positive selection (statistical

136 comparisons of models of evolution with and without diversifying selection). As such tests detect

137 only highly recurrent and rapid positive selection, we also investigated the 5\% of genes with the

138 highest $\mathrm{dN} / \mathrm{dS}$ values. High $\mathrm{dN} / \mathrm{dS}$ values, even if below 1, may be indicative of positive selection

139 at a few sites in the protein, although they may also result from relaxed selection. In several classes

140 of genes thought to be important for virulence and pathogenicity in entomopathogenic fungi (e.g.,

141 chitinases, lipases, proteases, small secreted proteins), only a few genes showed signs of selection

142 or species specificity. By contrast, we found that heat-labile enterotoxins were overrepresented

143 among both the species-specific genes and the genes with significant footprints of positive

144 selection. An analysis including enterotoxin-encoding genes from other entomopathogenic fungi

145 (Hypocreales), that do not manipulate host behavior, showed that positive selection was specific to

146 the ant-infecting genus Ophiocordyceps. These findings suggest that heat-labile enterotoxins are

147 important effectors involved in host adaptation and coevolution in entomopathogenic

148 Ophiocordyceps fungi.

149

\section{Materials and methods}

\section{$151 \quad$ Sampling and sequencing}

152 In 2015, we collected a sample of O. camponoti-leonardi (strain NK511ss-8) from

153 Kalayaniwattana district, in Chiang Mai province in Thailand, and a sample of $O$. camponoti154 saundersi (strain NK405ss-6) from the Phu Kiew National Park, in Chaiyaphum province. We used 
155 the reference genome of $O$. polyrhachis-furcata (strain BCC54312) (Wichadakul et al. 2015); we

156 aimed to improve the existing reference genome, but the original strain BCC54312 could not be 157 grown from the culture collection. We therefore collected three additional samples of this species 158 (strains NK275ss-12, NK142ss and NK294ss-20), in 2013 and 2014, from the same site as the 159 reference strain, in Khao Yai National Park, Nakhon Rachasima province. The collected samples 160 were isolated and grown as described by Wongsa et al. (2005). We complied with the Nagoya

161 protocols on access and benefit-sharing, by obtaining authorization from the Department of 162 National Parks, Wildlife and Plant Conservation (DNP) at the Ministry of Natural Resources and

163 Environment of Thailand for all strain collections. After two to three months of growth on Grace

164 Insect Cell Medium (Sigma-Aldrich), the mycelia and spores were harvested and DNA was 165 extracted with the NucleoSpin® Soil kit (Macherey-Nagel). The long incubation period is due to 166 the fact that $O$. unilateralis species in Thailand are very fastidious to grow, requiring few steps of 167 enlarging the culture scale to a sufficient level for DNA extraction. Genomic libraries were 168 constructed (150 bp paired-end reads) for sequencing with an Illumina HiSeq3000 machine at the 169 GenoToul platform (Toulouse, France).

170

171 Read pretreatment, de novo assembly and improvement of the reference genome

172 The raw reads were trimmed to remove adapters and low-quality bases from their ends $(q>$ 173 20). Duplicate reads were removed using Picard Tools MarkDuplicate. The reference genomes for 174 O. camponoti-leonardi and O. camponoti-saundersi were assembled de novo with SPAdes 175 (Bankevich et al. 2012), which progressively integrates k-mers of increasing size. The k-mer sizes 176 used were 21, 33, 55, 77, 99, 119, and 127 for NK405ss-6, and 21, 33, 55, 77, 99 and 115 for 
177 NK511ss-8. The appropriate maximum k-mer sizes were estimated with Kmergenie (Chikhi and 178 Medvedev 2013).

179 The reads obtained for the new O. polyrhachis-furcata samples were used to fill gaps in the

180 existing reference genome of this species with GapFiller (Boetzer et al. 2012), which mapped the

181 reads onto the reference sequence over the regions flanking the gaps and identified a consensus

182 between reads overlapping the gaps. In total, 175 of 3915 gaps were closed (identifying around 1.6

$183 \mathrm{Mb}$ from a total gap length of $2.4 \mathrm{Mb}$ in the reference genome).

\section{Gene prediction and functional annotation}

186 Gene prediction was based exclusively on scaffolds of more than $1 \mathrm{~kb}$ in length, and

187 involved a two-round approach based on MAKER (Cantarel et al. 2008). Gene sets were initially

188 predicted with CEGMA (Parra et al. 2007) and GeneMark-ES (Lomsadze et al. 2005), and were

189 then used as inputs into MAKER for the first round of prediction. The predicted proteins and

190 transcripts identified in previous studies on O. polyrhachis-furcata (Wichadakul et al. 2015) were

191 also used as a training set for MAKER. The predicted gene set from this first round was then fed

192 into SNAP (Korf 2004) and Augustus (Keller et al. 2011). The output of these two tools was then

193 fed back into MAKER for a second round of prediction.

194 The predicted proteins were annotated with InterProScan 5 (Jones et al. 2014), which also

195 associated the protein domains detected with sequences in the Pfam (Finn et al. 2016) and KEGG

196 (Ogata et al. 1999; Kanehisa et al. 2016) databases and with Gene Ontology (GO) terms. Small

197 secreted proteins (SSPs) were identified as proteins of less than 300 amino acids with signal

198 peptides but no transmembrane signature detected by SignalP (Petersen et al. 2011). Proteolytic

199 enzymes were also annotated, by Blast analysis of the predicted proteins against the MEROPS 
200 database (Rawlings et al. 2016) with a threshold e-value of $1 \mathrm{e}^{-20}$. Enzymes with activity against

201 carbohydrates were annotated with dbCAN (Yin et al. 2012); only genes with Pfam domains

202 consistent with those of the CAZYme database were retained. InterProScan recognized glycoside

203 hydrolase domains for some genes that were not detected by the CAZYme analysis toolkit; these

204 genes were also retained. The core genes of secondary metabolic gene clusters (SMGCs) were

205 predicted with SMURF (Khaldi et al. 2010), based on Pfam and Tigrfam domains and on gene

206 positions on scaffolds . SMGCs were predicted with the fungal version of antiSMASH (Weber et

207 al. 2015). SMGC homology across species was inferred with BiG-SCAPE (Navarros-Munõz J.,

208 https://git.wageningenur.nl/medema-group/BiG-SCAPE/wikis/home), which classified SMGCs

209 into families on the basis of Jaccard similarity indices between clusters. RepeatMasker was used

210 to predict repetitive elements for the three species from Thailand.

\section{Orthology and phylogenomics}

213 In addition to the predicted proteins from the de novo assembled and improved genomes of

214 O. unilateralis species from Thailand, we also included in our analyses the predicted proteins of

215 other ant-infecting Ophiocordyceps fungi specific to different ant species and originating from

216 different geographic areas (De Bekker et al. 2017). We used the available genomes from two

217 additional $O$. unilateralis s.l. species (O. kimflemingiae from the USA and $O$. camponoti-rufipedis

218 from Brazil), from two cryptic species of O. australis s.l., from Ghana and Brazil (De Bekker et al.

219 2017), and from O. subramanianii s.l., also from Ghana. The predicted proteins corresponding to

220 all these genomes were subjected to Blast comparisons with each other, with a significance

221 threshold e-value of $1 \mathrm{e}^{-5}$. The Blast results were used as input for orthAgogue (Ekseth et al. 2014),

222 a tool for the rapid inference of orthologous groups with the Markov clustering algorithm (MCL, 
223 Dongen 2000). This algorithm recovers species-specific paralogous groups, with genes from a

224 given species considered to be more closely related to each other than to any other gene in any

225 other species. The functional annotations obtained for O. polyrhachis-furcata were transferred to

226 the other species for gene copies in the same orthologous group. Species-specific paralogous genes

227 were annotated as described above. We analyzed GO term enrichment among species- or complex-

228 specific paralogs, with the topGO package in R (Alexa and Rahnenfuhrer 2016). Fisher's exact

229 tests were used to compare gene counts between paralogous species-specific or complex-specific

230 groups and the whole gene set for the species or complex, respectively.

231 Sequences within all orthologous groups were aligned with MACSE (Ranwez et al. 2011)

232 for further analyses. A phylogenetic tree with bootstrap support was constructed according to the

233 GTRCAT model under RaxML-HPC v8.1.5 (Stamatakis 2014), exclusively with the nucleotide

234 sequences for all the one-to-one orthologous groups in which each species was represented.

Detection of positive selection

Pairwise ratios of non-synonymous-to-synonymous substitutions (dN/dS) were calculated

238 between species (Yang and Nielsen 2000) with the yn00 program implemented in PAML v.4.8a

239 (Yang 2007). The mean pairwise $\mathrm{dN} / \mathrm{dS}$ ratios were calculated and used to assess variation across

240 single-copy orthologous groups with at least 4 species represented. Groups with dS $<0.01$,

241 potentially resulting in inaccurate $\mathrm{dN} / \mathrm{dS}$ estimates, and groups with excessively high dN/dS (>10)

242 ratios, were discarded. The functions overrepresented among the 5\% of genes with the highest

$243 \mathrm{dN} / \mathrm{dS}$ ratios were inferred by an analysis of enrichment in GO terms. A mean dN/dS >1 for a given

244 gene indicates positive selection, whereas high $\mathrm{dN} / \mathrm{dS}$ values below 1 can be due to positive

245 selection on a small number of sites within the protein or to relaxed selection. 
We also formally tested for positive selection by performing site-model likelihood ratio 247 tests (LRTs) with the CodeML program implemented in PAML v.4.8a (Yang 2007), excluding 248 gaps and ambiguous sites and using trees inferred under GTRCAT model from respective 249 orthologous groups. CodeML estimates the parameter omega $(\omega=\mathrm{dN} / \mathrm{dS})$ by maximum likelihood 250 methods, allowing variation between sites. While the pairwise measures above only approximate 251 synonymous and non-synonymous rates, likelihood ratio tests (LRTs) statistically compare two 252 models of evolution, one in which $\omega<1$ (null model) at all sites and another in which $\omega>1$ at 253 some sites (alternative hypothesis of positive selection); LRTs thus indicate whether a model with 254 positive selection is more likely than a model without positive selection. We compared the M7 255 (beta distribution of $\omega$ ) and M8 (beta distribution of $\omega$ with a proportion of sites with $\omega>1$; Nielsen 256 \& Yang 1998, Yang et al. 2000) models, and the M8a (similar to M8 but with a category of sites 257 evolving with $\omega=1$ ) and M8 (Swanson et al. 2003) models in LRTs. Only genes with a $p$-value 258 below 0.05 after false-discovery rate (fdr) correction were considered significant. The M7 vs. M8 test is known to lack robustness when the probability mass is located around $\omega=1$, in which case 260 this test gives a high proportion of false positives; under these conditions, the M8a vs. M8 test is 261 preferred (Swanson et al. 2003). We ensured the robustness of our results by considering only 262 genes in which significant evolution under positive selection was detected in both tests. We 263 checked for enrichment in particular GO terms among the genes evolving under positive selection.

264 We also investigated whether genes encoding heat-labile enterotoxins evolved under 265 positive selection specifically in ant-infecting Ophiocordyceps and not in other Hypocrealean 266 fungi. We therefore downloaded predicted gene sequences from other Hypocrealean fungi that 267 were annotated as putative heat-labile enterotoxins from the Ensembl Genome database (Herrero 268 et al. 2016). Putative heat-labile enterotoxin genes were retrieved for 14 entomopathogenic fungi 
269 (one strain per species) (Additional Table S1): Metarhizium anisopliae ARSEF23 (24 genes), $M$.

270 acridum CQMa 102 (3 genes) (Pattemore et al. 2014); M. album ARSEF1941 (12 genes), M.

271 brunneum ARSEF3297 (32 genes), M. guizhouense ARSEF977 (32 genes), M. majus ARSEF297

272 (32 genes) (Hu et al. 2014); M. rileyi RCEF4871 (3 genes), Isaria fumosorosea ARSEF2679 (5

273 genes), Aschersonia aleyrodis RCEF2490 (14 genes), Cordyceps confragosa RCEF1005 (6 genes),

274 C. brongniartii RCEF3172 (30 genes) (Shang et al. 2016), Cordyceps militaris CM01 (one gene,

275 Zheng et al. 2011), Beauveria bassiana ARSEF2860 (6 genes, Xiao et al. 2012); and

276 Ophiocordyceps sinensis Co18 (13 genes, Xia et al. 2017). We also included putative heat-labile

277 enterotoxin sequences from two nematode-killing fungi: Purpureocillium lilacinum PLBJ-1 (two

278 genes, Wang et al. 2016) and Pochonia chlamydosporia 170 (four genes). Orthologs between these

279 sequences and the putative enterotoxins of $O$. unilatealis species studied here were identified. The

280 occurrence of clade-specific positive selection in $O$. unilateralis was assessed with branch model

281 LRTs in PAML (Yang 1998; Yang and Nielsen 1998) and with the BUSTED test, an alignment-

282 wide test of episodic positive selection (Murrell et al. 2015). Both these tests are log-likelihood

283 ratio tests comparing a model in which positive selection is allowed in the foreground branches

284 (i.e. the clade of interest) to the null model in which positive selection is not allowed. The branch

285 model (Yang and Nielsen 1998), as implemented in PALM, detects positive selection by allowing

286 a candidate clade to have a $\mathrm{dN} / \mathrm{dS}$ ratio higher than those of the other branches (background

287 branches) without taking into account variation between sites or allowing variation between

288 branches of the same category. By contrast, BUSTED is a stochastic test using information from

289 all sites and branches; it is therefore considered to have greater statistical power (Murrell et al.

290 2015). 


\section{Results}

\section{General genome features}

294 The three reference genomes of closely related species sequenced here differed

295 considerably in size, O. camponoti-saundersi (OCS) being the largest (49.26 Mb), followed by $O$.

296 polyrhachis-furcata (OPF) (43.25 Mb) and O. camponoti-leonardi (OCL) (37.91 Mb). These

297 differences probably partly reflect methodological differences as the OPF genome is an improved

298 version of a genome sequenced with a different technology (454 pyrosequencing combined with

299 Illumina mate-pair sequencing, Wichadakul et al. 2015). OCL and OCS were sequenced and

300 assembled with the same methodology, so the observed differences probably reflect genuine

301 differences in genome size. OCS also had more scaffolds (1700) than OCL (531). OPF had fewer

302 scaffolds and larger contigs, due to the use of variable-size mate-pair libraries (Wichadakul et al.

303 2015) (Table 1). These genomes are markedly larger than those reported for $O$. kimflemingiae

304 (OKi: $23.91 \mathrm{Mb}$ ), O. camponoti-rufipedis (OCR: 21.91 Mb), O. australis s.l. from Brazil (OAB:

$30523.32 \mathrm{Mb}$ ) and from Ghana (OAG: 22.19 Mb), and O. subramanianii s.l. (OSS: $32.31 \mathrm{Mb}$ ), but all

306 these previously published genomes were more fragmented than our assemblies (Table 1).

307 Despite the differences in genome size, the numbers of predicted genes were of a same

308 order of magnitude across species (Table 1), although the number of predicted genes was

309 nevertheless largest for OSS. For the three species from Thailand, OPF had the largest number of

310 predicted genes, probably because the protein and transcript training set used for prediction came

311 from this species. The number of SSPs was similar between the three Thai species. The number of

312 genes with assigned Pfam domains or InterPro classification and the complete predicted gene sets 
313 obtained by core eukaryotic genes mapping (CEGMA) were also very similar in the three species

314 ( 95\%: Table 1), but smaller than those for species from the New World ( 99\%).

\section{Orthology and phylogenomics}

317 The genomes used in this study were sequenced from individuals belonging to one of the

318 three species complexes: O. unilateralis s.l., O. australis s.l. and O. subramanianii s.l. Most of the

319 genes were common to all three complexes (Fig. 1a): 8,554 orthologous groups were retrieved,

3205,718 of which were common to all complexes. For orthologous groups present in only one of the

321 three complexes (Supporting information: Table S2), pathogenesis (GO:0009405) was the function

322 displaying the most significant enrichment in all complexes (Bonferroni-corrected $p$-values: $2 \mathrm{e}^{-10}$

323 for O. unilateralis s.l., 0.016 for O. australis s.l., $3.4 \mathrm{e}^{-5}$ for O. subramanianii s.l.), mostly due to

324 the presence of genes encoding putative heat-labile enterotoxins in these complex-specific genes.

325 Complex-specific genes were also found to be enriched in inter-species interactions and multi-

326 organism process functions.

327 Within each species complex, most of the genes were common to several species (Fig. 1b and

328 1c). The function pathogenesis was found to be overrepresented among species-specific genes

329 (Supporting information: Tables S3 - S4), due to the presence of genes encoding heat-labile

330 enterotoxins, andSSPs (Tables 2 and 3). In particular, we detected an overrepresentation of SSPs

331 among the genes unique to $O$. kimflemingiae $(p$-value $=0.003$ ) relative to $O$. unilateralis s.l.

332 compex, and among the genes unique to O. australis from Brazil relative to $O$. australis s.l.

333 complex ( $p$-value $=0.001)$. None of these species-specific SSPs had a predicted function,

334 suggesting an expansion of rapidly evolving families of effectors (Kim et al. 2016). 
There were 4,651 orthologous groups common to all eight genomes. We used a subset of

3364,014 single-copy orthologous groups common to all species to construct a phylogenetic tree (Fig.

337 2). This tree recovered the expected relationships between the sibling species from Thailand, with

338 O. polyrhachis-furcata being the most closely related to O. camponoti-leonardi (Kobmoo et al.

339 2012, 2015); the species from the Americas, O. kimflemingiae and O. camponoti-rufipedis,

340 clustered together but were separate from those from Thailand, corresponding to the separation

341 between the Old and New Worlds observed in a previous study (Evans et al. 2018). The two $O$.

342 australis s.l. species were grouped together and formed, with $O$. subramanianii, an outgroup to the

343 O. unilateralis complex.

\section{Variation of $d N / d S$ across genomes and putative functions}

346 The median pairwise $\mathrm{dN} / \mathrm{dS}$ ratio was 0.081 , indicating that most single-copy orthologs

347 evolved under strong purifying selection (Fig. 3a). No orthologous group had dN/dS > 1

348 (Supporting information: Table S5). We investigated the putative functions of the 5\% of genes with

349 the highest dN/dS values (297 genes) (Supporting information: Table S5), even if these ratios were

350 below 1, as this could be indicative of positive selection at a small number of sites in the protein,

351 although relaxed selection cannot be excluded for $\mathrm{dN} / \mathrm{dS}<1$. Fisher's exact tests for enrichment in

352 GO term annotation among the $5 \%$ of genes with the highest $\mathrm{dN} / \mathrm{dS}$ values relative to all single-

353 copy orthologous groups (i.e., $\mathrm{dN} / \mathrm{dS}>0.253$ ) indicated that the functions pathogenesis,

354 interspecies interaction between organisms and multi-organism process (respective Bonferroni-

355 corrected $p$-value $=3.4 \mathrm{e}-17,2.2 \mathrm{e}-18$ and $5.5 \mathrm{e}-180.005)$ were the most significantly

356 overrepresented. The genes annotated with the pathogenesis (GO:0009405) GO term and with a

$357 \mathrm{dN} / \mathrm{dS}$ ratio in the top 5\% were all putative heat-labile enterotoxin alpha chains. Twenty 
358 orthologous groups annotated as heat-labile enterotoxins were found in one-to-one orthologous

359 groups common to at least four species, thirteen of which had dN/dS values in the top $5 \%$.

360 Enterotoxins had a significantly higher mean dN/dS than the genome as a whole ( $t$-test: Bonferroni-

361 corrected $p$-value $\left.=5.19 \mathrm{e}^{-08}\right)($ Fig. $3 b)$. The GO terms relating to glycoside hydrolases $(\mathrm{GH}$

362 families: chitinases GH18, trehalases GH37), proteases and lipases, essential to the primary

363 functions of entomopathogenic fungi, such as nutrient acquisition and host cell penetration, were

364 not overrepresented among the $5 \%$ of genes with the highest $\mathrm{dN} / \mathrm{dS}$ values. The mean $\mathrm{dN} / \mathrm{dS}$ values

365 for these gene families were not significantly higher than that for the whole genome ( $t$-tests;

366 chitinases: bonferroni-corrected $p$-value $=0.926$, lipases: bonferroni-corrected $p$-value=1.00,

367 proteases: bonferroni-corrected $\mathrm{p}$-value $=1.00$, trehalases: bonferroni-corrected $p$-value $=1.00)$

368 (Fig. 3b). None of the core genes in secondary metabolic gene clusters was found among the 5\%

369 of genes with the highest $\mathrm{dN} / \mathrm{dS}$ values, and their mean $\mathrm{dN} / \mathrm{dS}$ value was not significantly higher

370 than that of other genes $(t$-test: bonferroni-corrected $p$-value $=0.885)($ Fig. $3 b)$. The genes encoding

371 putative SSPs had a significantly higher dN/dS ratio than non-SSP genes $(t$-test: $p$-value=2.2e-16)

372 (Fig. 3b). This suggest that a higher proportion of genes may evolve under positive selection among

373 SSP-encoding genes than among other genes.

375 Formal tests for positive selection

376 LRTs (likelihood ratio tests comparing models with or without positive selection) were 377 performed as formal genome-wide tests for positive selection. Of the 5,950 single-copy 378 orthologous groups common to at least four species, 759 and $244(12.76 \%$ and $4.10 \%)$ were found

379 to be evolving under positive selection in comparisons of the models M7 vs. M8 and M8a vs. M8,

380 respectively (Supporting information: Table S6), with 144 genes found to be evolving under 
381 positive selection in both tests. The functions of pathogenesis and toxin activity were significantly

382 overrepresented among the annotations for these 144 genes (Table 4). This enrichment in the

383 pathogenesis and toxin activity functions was due entirely to enterotoxin genes. Five to seven (25\%

$384-35 \%)$ putative heat-labile enterotoxin-coding genes were identified as evolving under positive

385 selection, depending on the evolution model tested (Fig. 4 and Supporting information: Table S7).

386 These genes were also predicted to have a function in the extracellular region (GO:0005576), and

387 most were predicted to have signal peptides. Enrichment was also observed for functions relating

388 to kinases (e.g. ATP binding, kinase activity, transferase activities: Table 4.); significant results

389 were obtained for 15 to $31(8.1 \%$ - $16.8 \%)$ kinases in LRTs and eight kinases gave significant

390 results in both tests (Fig. 4 and Table S7). Kinases catalyze the transfer of a phosphate group from

391 a high-energy molecule (ATP) to a substrate and are involved in various cellular processes. The

392 proportion of kinases evolving under positive selection was lower than that of heat-labile

393 enterotoxins (Fig. 4), but the numbers of kinases and heat-labile enterotoxins evolving under

394 positive selection were similar, and these two functions were overrepresented among the genes

395 evolving under positive selection. Most of these kinases were annotated as protein kinases,

396 histidine kinases and phosphatidylinositol 3 and 4-kinases. These families of kinases are well

397 known to be involved in cell signaling, essential for pathogen growth and survival and, thus, for

398 pathogenesis and virulence (Lee et al. 2016).

399 The functions relating to hydrolytic enzymes important for pathogenesis (glycoside

400 hydrolases, lipases, proteases) were not overrepresented among the genes evolving under positive

401 selection. Indeed, the proportions of genes in these families found to be under positive selection

402 were markedly smaller than those for heat-labile enterotoxins (Fig. 4). Nevertheless, several of the

403 genes from these gene families were found to evolve under positive selection in model tests 
404 (Supporting information: Table S7) and can be considered good candidates for involvement in 405 coevolution and host specificity. One to three of the 11 chitinases (GH18) presented significant 406 footprints of positive selection depending on the evolution model considered, and significant $P$ 407 values were obtained in all tests for one of these enzymes. Chitinases are involved in the 408 degradation of the insect cuticle, a major component of the insect exoskeleton, and in the 409 degradation and remodeling of fungal cell walls (Adams 2004; Langner and Göhre 2016). Other $410 \mathrm{GH}$ families converging to various functions such as cellulase, glucanase, glucosidase, 411 galactosidase (e.g., GH5, GH16, GH47, GH76) also included a few genes displaying significant 412 tests of positive selection (Supporting information: Table S7). Neither of the two trehalases 413 (GH37), which are thought to play important roles in nutrient acquisition within the host body, 414 displayed significant signs of positive selection.

415 Zero to four of the nine subtilisin-like (MEROPS family S08 and S53) and trypsin-like 416 proteases (MEROPS familyS01), which are considered to act as cuticle-degrading proteases, 417 presented significant footprints of positive selection, depending on the evolution model considered. 418 Zero to one of 16 putative aspartyl proteases (MEROPS family A01) was found to evolve under 419 positive selection following different models. However, none of these proteases yielded significant 420 results in both tests (Fig. 4). Two to six of the 39 putative lipases yielded significant $P$-values in 421 positive selection tests, and only one yielded significant $P$-values in both tests (Fig. 4; Supporting 422 information: Table S7).

423 One to four of the seven core genes of secondary metabolites displayed significant 424 signatures of positive selection, depending on the evolution model considered (Supporting 425 information: Table S7). The only gene to yield significant $P$-values in both tests (orthologous group 426 ORTHAg2248, Supporting information Table S7) encoded a polyketide synthase (PKS)-like 
427 protein with a beta-ketoacyl synthase domain. Beta-ketoacyl synthase is involved in fatty-acid 428 biosynthesis and has been shown to be involved in the production of polyketide antibiotics in fungi 429 (Beck et al. 1990). The gene encoding this enzyme is part of a secondary metabolic gene cluster 430 that is highly syntenic across the species of the $O$. unilateralis complex, but located in different 431 clusters in O. australis and in O. subramanianii (Fig. 5).

432 We also investigated whether the genes previously identified as encoding possible 433 "neuromodulators" (de Bekker et al. 2017), based on their overexpression during the manipulation 434 of ant behavior, showed signs of positive selection. In total, 12 to 41 of these genes yielded 435 significant results in tests for positive selection (Supporting information: Table S8). Five genes 436 yielded significant results in both tests. These genes encoded a short-chain dehydrogenase, a DNA 437 mismatch repair protein (MutC), a DNA replication factor, an ATPase and a protein with no 438 functional annotation. Seven other genes yielded results only in the M8a vs. M8 test, which is more 439 robust than the M7 vs. M8 test. These seven genes included oxidoreductases clearly involved in 440 metabolic reactions: a protein with a ferric reductase transmembrane-like domain, a flavodoxin 441 oxidoreductase, and an oxidoreductase binding to a molybdopterin cofactor with a cytochrome b5-

442 like heme/steroid-binding domain. The first of these genes was shown to be associated with iron 443 uptake in yeast (Roman et al. 1993), whereas the product of the second mediates iron-free electron 444 transfer. The third of these genes may encode a nitrate reductase or sulfite oxidase, both of which 445 are involved in nitrogen assimilation. These putative neuromodulators thus seem to be involved in 446 host resource utilization. The neurological disorder displayed by zombie ants infected with 447 Ophiocordyceps may result from the pathogen outcompeting the host for iron and nitrogen. 448 

2015) suggest that heat-labile enterotoxin genes are candidate genes for host-specific adaptation.

453 We therefore investigated whether the positive selection detected above was specific to the ant454 infecting Ophiocordyceps species or general to Hypocrealean entomopathogenic and nematode455 killing fungi. Thirty-six orthologous groups of heat-labile enterotoxin genes were inferred for a 456 group of 16 Hypocrealean entomopathogenic and nematode-killing fungi in addition to our eight 457 focal species (Supporting information: Table S1); 22 of these orthologous groups included at least 458 one sequence from the ant-infecting Ophiocordyceps, and 10 (42\%) of these groups included only 459 sequences from the ant-infecting Ophiocordyceps species. We further analyzed the only group 460 (ORTHAgEnt13) common to at least four of the ant-infecting Ophiocordyceps species considered 461 and sequences recovered from other species from Hypocreales, for which both site-model LRTs 462 for positive selection were significant. This group included five sequences each from an $O$. 463 unilateralis species. In a maximum likelihood tree, all the $O$. unilateralis sequences were located 464 on the same branch (Fig. 6). The PAML branch-model LRTs indicated that this gene was evolving 465 under positive selection specifically in the $O$. unilateralis clade ( $p$-values $<0.001$ ). The branch at 466 the base and the internal branches of the $O$. unilateralis clade therefore had significantly higher $467 \mathrm{dN} / \mathrm{dS}$ ratios than the other branches (Fig. 6). The BUSTED test, which is similar to PAML branch 468 tests but considered more powerful, also gave a significant result ( $p$-value $=6.16 \mathrm{e}-14$ ). 
Comparative genomic studies of closely related species of fungal pathogens have shown

473 that, in general, genes involved in adaptation, particularly those involved in virulence and

474 pathogenicity, are species-specific, highly divergent and/or under diversifying selection, as a result

475 of the arms race between host and pathogen or specialization on new hosts (Ghanbarnia et al. 2015;

476 Huang et al. 2014; Plissonneau et al. 2017; Stukenbrock et al. 2011). We therefore used an

477 evolutionary comparative genomic approach for identifying genes underlying host adaptation in

478 ant-infecting Ophiocordyceps from three species complexes (O. unilateralis s.l., O. australis s.l.

479 and O. subramanianii s.l.). Genome comparisons showed that species complex-specific genes were

480 enriched in genes associated with the function pathogenesis which included genes encoding heat-

481 labile enterotoxins. The species-specific genes were also enriched in this function. However, most

482 species-specific genes lacked functional annotation, perhaps due to their rapid evolution as part of

483 the arms race between pathogen and host, resulting in homology no longer being detectable. Most

484 of the small secreted proteins (SSPs), in particular, lacked predicted functions, but these proteins

485 were particularly abundant among the species-specific genes. SSPs may act as effectors in

486 pathogenicity, but the validation of their function requires further studies.

487 Heat-labile enterotoxin genes were also overrepresented in the orthologous groups with the

488 highest rates of amino-acid differences between species, suggesting the occurrence of diversifying

489 selection, which was confirmed by formal tests comparing models with and without positive

490 selection. Furthermore, in the cases in which orthologs of enterotoxin genes were found in other

491 entomopathogenic fungi, we inferred that positive selection was specific to the ant-infecting

492 Ophiocordyceps clade. These findings support the view that heat-labile enterotoxins are effectors

493 involved in host adaptation, as previously suggested based on observations of enterotoxin

494 overexpression during manipulation of the behavior of the diseased ants (de Bekker et al. 2015) 
and of the species-specific nature of behavioral manipulation (de Bekker et al. 2014, Sakolrak et

496 al. 2018). The proximal mechanisms via which enterotoxins act during infection and the

497 manipulation of host behavior remain unclear, but it has been suggested that these molecules

498 interfere with the chemical communication of social insects; bacterial enterotoxins have been

499 shown to affect pheromone production in boll weevils (Wiygul and Sikorowski 1986, 1991).

500 Alterations to chemical communication may contribute to the modification of behavior in infected 501 ant hosts.

\section{Minor role of the cuticle in exerting selective pressure leading to diversifying selection}

Hypocrealean entomopathogenic fungi are known to infect their insect hosts by penetrating

505 the cuticle from the outside (Boomsma et al. 2014). An array of hydrolytic enzymes, including

506 chitinases, lipases and proteases, is required to break through the insect cuticle (Ortiz-Urquiza and

507 Keyhani 2013). Chitins are major constituents not only of insect cuticles, but also of fungal cell

508 walls (Lagner and Göhre 2016) while lipids are a major component of the epicuticle waxy layer

509 (Jarrold et al. 2007; Pedrini et al. 2013). Proteases are important for the penetration of the cuticle

510 by fungi, and have been shown to be virulence factors for the infection of insect hosts (Shah et al.

511 2005). Subtilisin proteases have been shown to play a particularly important role in regulating

512 insect host specificity through the differential expressions of specific isoforms (Bye and Charnley

513 2008; Mondal et al. 2016). We therefore hypothesized that the genes encoding chitinases, proteases

514 and lipases might have evolved under diversifying selection. However, we found footprints of

515 positive selection for only a few of putative genes encoding these enzymes in the ant-infecting

516 Ophiocordyceps species. This challenges the widely accepted view that the insect cuticle, as a

517 major barrier to infections, exerts a strong selective pressure on entomopathogenic fungi, leading 
518 to different host ranges (Boomsma et al. 2014; Ortiz-Urquiza and Keyhani 2013; Wang and St.

519 Leger 2005; Wang et al. 2011). Nevertheless, as the fungi in the three ant-infecting complexes

520 considered here are all pathogens of formicine and ponerine ants, our findings do not rule out

521 diversifying selection occurring across larger phylogenetic scales. These enzymes may be highly

522 conserved among pathogens of formicine and ponerine ants, providing a common arsenal for

523 attacking taxonomically related ants. There may also be constraints in the host or the fungus

524 preventing rapid coevolution through changes to these molecules.

\section{$526 \quad$ Utilization of host resources}

527 Once inside the host, the pathogen requires other hydrolases for carbon assimilation.

528 Efficient nutrient uptake from the host allows optimal proliferation of the fungus within its host, 529 and ultimately leads to insect death (Luo et al. 2014). It has, therefore, been suggested that host

530 resource utilization is crucial for host specificity (Gillespie et al. 2000). Trehalases, in particular,

531 probably play an important role in this respect. Indeed, the fly pathogen Entomophthora muscae

532 (Entomorphthorales) carries more trehalase-encoding genes in its genome than its close relative,

533 the generalist Conidiobolus coronatus, which is a non-obligate pathogen (De Fine Licht et al.

534 2017). We identified two trehalases with no positive selection signature as conserved across all

535 species. Other glycoside hydrolases and lipases may be involved in breaking down primary carbon

536 sources (Ortiz-Urquiza and Keyhani 2013; Schrank and Vainstein 2010). However, the evidence

537 for positive selection is less robust for these enzymes. Thus, diversifying selection in ant538 pathogenic Ophiocordyceps fungi probably acts less strongly on the function of carbon assimilation

539 than on enterotoxins. Again, there may be constraints preventing the rapid evolution of host cuticle

540 or fungal hydrolase and lipase functions. 
541 Nitrogen also plays a key role in the proliferation of entomopathogenic fungi (Luo et al.

542 2014). However, our results suggest that initial nutrient acquisition via proteinases is not under

543 strong diversifying selection. Genes evolving under positive selection were not enriched in

544 functions related to the assimilation of nitrogen or amino-acid synthesis.

545 In addition to carbon and nitrogen, iron uptake is also crucial for pathogen success (Bairwa

546 et al. 2017, Haas 2012, Sutak et al. 2008). The candidate neuromodulator genes found to be under

547 positive selection included iron-related oxidoreductases. In particular, one of the proteins identified

548 had a ferric-reductase transmembrane domain, and another was a flavodoxin oxidoreductase.

549 Proteins with ferric-reductase transmembrane domains have been shown to be crucial for ferric

550 iron uptake in yeast (Roman et al. 1993), whereas flavodoxin is an iron-free electron-transfer

551 protein facilitating a range of metabolic reactions in the absence of iron. Specialist

552 entomopathogens kill their hosts more slowly than generalists (Boomsma et al. 2014). In such a

553 context, ant-specific Ophiocordyceps might be expected to have developed strategies for hijacking

554 resources from the host. The efficient acquisition of iron and an ability to divert its use may be the

555 key to outcompeting the host during infection.

556

557 The role of kinases and signal transduction

$558 \quad$ Kinase enzymes are widely recognized as participating in various cellular processes, crucial

559 to growth and survival (Lee et al. 2016). The genes under positive selection in the ant-infecting

560 Ophiocordyceps were enriched in kinase-related functions. Most were clearly related to signal

561 transduction, which plays a crucial role in interactions between hosts and pathogens (Bahia et al.

562 2018). Pathogens sense and respond to environmental stimuli, including the expression of virulence

563 factor regulatory systems, in the hostile conditions of the host immune system. As extremely 
564 specialized pathogens, ant-infecting Ophiocordyceps fungi must fine-tune their responses in the 565 host body.

\section{Importance of lipid metabolism}

Many entomopathogenic fungi are also thought to deploy a plethora of metabolites and

569 toxins within the bodies of their hosts (Schrank and Vainstein 2010; Singh et al. 2016). The nature

570 of these molecules probably differs between groups of insect-pathogenic fungi and remains to be

571 precisely determined, but the principal molecules include polyketides (PKs) and non-ribosomal

572 peptides (NRPs) (Gallo et al. 2013). We detected significant footprints of positive selection in some

573 of the core genes of secondary metabolites. The most notable case concerned a PKS-like function

574 involved in lipid biosynthesis. Lipids have been shown to be involved in pathophysiological

575 processes in pathogenic fungi, but the role of the lipid signaling network in host-specific

576 pathogenicity remains to be determined (Singh and Poeta 2011). Kinases are also known to

577 participate in lipid signaling pathways, and the kinases with significant footprints of positive

578 selection identified included phosphatidylinositol 3 and 4-kinase. The phosphorylated form of

579 phosphatidylinositol plays an important role in lipid and cell signaling (Funaki et al. 2000). Lipid

580 metabolism thus seemed to be subject to diversifying selection, although to a lesser extent than

581 heat-labile enterotoxins.

\section{Conclusions}

584 We focused on three ant-infecting species complexes from genus Ophiocordyceps, 585 including closely related species. Complex- and species-specific genes were found to be enriched

586 in genes for heat-labile enterotoxins, and this gene family was found to be evolving under positive 
587 selection to a greater extent than other candidate gene families. Our results thus suggest that the 588 specific adaptation and coevolution of specialist species in the ant-infecting Ophiocordyceps fungi

589 to their hosts is dependent on selection occurring within the body of the host rather than during

590 cuticle penetration. By contrast, we detected little positive selection on lipases, proteases or

591 chitinases, although we did identify a few interesting candidate genes from these groups.

592 Comparative genomic studies of entomopathogenic fungi remain scarce, and the few studies that

593 have been performed have focused exclusively on species of agricultural or medical interest. The

594 findings of this study improve our understanding of the mechanisms of fungal adaptation to insect

595 hosts, and future studies on fungal pathogens associated with other groups of insects should provide

596 more general insight into the adaptation of entomopathogenic fungi and a more documented

597 comparison with the mechanisms of adaptation in fungal pathogens of plants. The insect innate

598 immune response seems to be much more specific than that in plants, suggesting a certain level of

599 acquired immune response (Cooper and Eleftherianos 2017). Fungal pathogens of insects would

600 be expected to display extensive expansions and contractions of gene families, as observed in plant

601 pathogens, but the target functions may be different. Additional insight gleaned from

602 entomopathogenic fungi would help to improve our general understanding of the mechanisms of

603 adaptive evolution in eukaryotes.

604

\section{Acknowledgments}

606 This work was supported by the Marie Sklodowska Curie Action $N^{\circ} 655278$ and Thailand 607 Research Fund (TRF) Young Scientist Grant (TRG5780162) to NK. We would like to thank 608 Alodie Snirc for advice concerning DNA extraction, Antoine Branca for suggestions about 
bioinformatic protocols, Rayan Chikhi for training in genome assembly, Jérome Collemare and

610 Jorge C. Navarro-Munoz for their guidance on using AntiSMASH and BigSCAPE, and Suchada

611 Mongkholsamrit and Kanoksri Tasanathai for the organization of sampling trips. We also would

612 like to sincerely thank Clarissa De Bekker and David P. Hughes for kindly sharing their data on

613 the candidate neuromodulators.

614

615

616

617

618

619

620

621

622

623

624

625

626

627

628

629

630

631

632

633

634

635

636

637

638

639

640

641

642

643

644

Adams, D. J. (2004). Fungal cell wall chitinases and glucanases. Microbiology, 150(7), 2029-2035. doi:10.1099/mic.0.26980-0

Aguileta, G., Lengelle, J., Chiapello, H., Giraud, T., Viaud, M., Fournier, E. et al. (2012). Genes under positive selection in a model plant pathogenic fungus, Botrytis. Infection, Genetics and Evolution, 12(5), 987-996. doi:10.1016/j.meegid.2012.02.012

Aguileta, G., Lengelle, J., Marthey, S., Chiapello, H., Rodolphe, F., Gendrault, A et al. (2010). Finding candidate genes under positive selection in Non-model species: Examples of genes involved in host specialization in pathogens. Molecular Ecology, 19(2), 292-306. doi:10.1111/j.1365294X.2009.04454.x

Aguileta, G., Refrégier, G., Yockteng, R., Fournier, E., \& Giraud, T. (2009). Rapidly evolving genes in pathogens: Methods for detecting positive selection and examples among fungi, bacteria, viruses and protists. Infection, Genetics and Evolution, 9(4), 656-670. doi:10.1016/j.meegid.2009.03.010

Albalat, R., \& Cañestro, C. (2016). Evolution by gene loss. Nature Reviews Genetics, 17(7), 379-391. doi:10.1038/nrg.2016.39

Alexa A and Rahnenfuhrer J (2016). topGO: Enrichment Analysis for Gene Ontology. R package version 2.28.0.

Anderson, J. P., Gleason, C. A., Foley, R. C., Thrall, P. H., Burdon, J. B., \& Singh, K. B. (2010). Plants versus pathogens: An evolutionary arms race. Functional Plant Biology, 37(6), 499-512. doi:10.1071/FP09304

Anderson, P. K., Cunningham, A. A., Patel, N. G., Morales, F. J., Epstein, P. R., \& Daszak, P. (2004). Emerging infectious diseases of plants: Pathogen pollution, climate change and agrotechnology drivers. Trends in Ecology and Evolution, 19(10), 535-544. doi:10.1016/j.tree.2004.07.021

Araùjo, J. P. M., Evans, H. C., Kepler, R., Hughes, D. P. (2017). Zombie-ant fungi across continents: 15 new species and new combinations with Ophiocordyceps. I. Myrmecophilous hirsutelloid species. Studies in Mycology, 90, 119-160.

Badouin, H., Gladieux, P., Gouzy, J., Siguenza, S., Aguileta, G., Snirc, A., Le Prieur, S., Jeziorski, C., Branca, A., Giraud, T. (2017). Widespread selective sweeps throughout the genome of model plant pathogenic fungi and identification of effector candidates. Molecular Ecology, 26, 2041-2062. doi: 
Bahia, D., Satoskar, A., Dussurget O. (2018). Cell signalling in host-pathogen interactions: The host point

Bairwa, G., Hee Jung W., Kronstad J. (2017). Iron acquisition in fungal pathogens of human. Metallomics: of view. Frontiers in Immunology, 9, 1-4. doi: 10.3389/fimmu.2018.00221

Bankevich, A., Nurk, S., Antipov, D., Gurevich, A. A., Dvorkin, M., Kulikov, A. S. et al. (2012). SPAdes: A New Genome Assembly Algorithm and Its Applications to Single-Cell Sequencing. Journal of Computational Biology, 19(5), 455-477. doi:10.1089/cmb.2012.0021

Baroncelli, R., Amby, D. B., Zapparata, A., Sarrocco, S., Vannacci, G., Le Floch, G. et al. (2016). Gene family expansions and contractions are associated with host range in plant pathogens of the genus Colletotrichum. BMC Genomics, 17(555), 1-17. doi:10.1186/s12864-016-2917-6

Barrett, L. G., \& Heil, M. (2012). Unifying concepts and mechanisms in the specificity of plant-enemy interactions. Trends in Plant Science, 17(5), 282-292. doi:10.1016/j.tplants.2012.02.009

Beck, J., Ripka, S., Siegner, A., Schiltz, E., Schweizer, E. (1990). The multifunctional 6-methylsalicylic acid synthase gene of Penicillium patulum. Its gene structure relative to that of other polyketide synthases. European Journal of Biochemistry, 192(2), 487-498.

Boetzer, M., Pirovano, W., Zerbino, D., Birney, E., Simpson, J., Wong, K. et al. (2012). Toward almost closed genomes with GapFiller. Genome Biology, 13(6), R56. doi:10.1186/gb-2012-13-6-r56

Boomsma, J. J., Jensen, A. B., Meyling, N. V, \& Eilenberg, J. (2014). Evolutionary Interaction Networks of Insect Pathogenic Fungi. Annu. Rev. Entomol, 59, 467-85. doi:10.1146/annurev-ento-011613162054

Bye, N. J., \& Charnley, A. K. (2008). Regulation of cuticle-degrading subtilisin proteases from the entomopathogenic fungi, Lecanicillium spp: Implications for host specificity. Archives of Microbiology, 189(1), 81-92. doi:10.1007/s00203-007-0296-8

Cantarel, B. L., Korf, I., Robb, S. M. C., Parra, G., Ross, E., Moore, B. et al. (2008). MAKER: An easy-touse annotation pipeline designed for emerging model organism genomes. Genome Research, 18, 188196. doi:10.1101/gr.6743907

Chikhi, R., \& Medvedev, P. (2014). Informed and automated k-mer size selection for genome assembly. Bioinformatics, 30(1), 31-37. doi:10.1093/bioinformatics/btt310

Cooper, D., \& Eleftherianos, I. (2017). Memory and specificity in the insect immune system: Current perspectives and future challenges. Frontiers in Immunology, 8(539), 1-6. doi:10.3389/fimmu.2017.00539

Dongen, S. V. Graph Clustering by Flow Simulation. PhD thesis, University of Utrecht, May 2000.

de Bekker, C., Ohm, R. A., Evans, H. C., Brachmann, A., Hughes, D. P. (2017). Ant-infecting Ophiocordyceps genomes reveal a high diversity of potential behavioral manipulation genes and a possible major role for enterotoxins. Scientific Reports, 7, 12508. doi:10.1038/s41598-017-12863-w

de Bekker, C., Ohm, R. A., Loreto, R. G., Sebastian, A., Albert, I., Merrow, M. et al. (2015). Gene expression during zombie ant biting behavior reflects the complexity underlying fungal parasitic behavioral manipulation. BMC Genomics, 16(1), 1-23. doi:10.1186/s12864-015-1812-x 
684

685

686

687

688

689

690

691

692

693

694

695

696

697

698

699

700

701

702

703

704

705

706

707

708

709

710

711

712

713

714

715

716

717

718

719

720

721

722

723

de Bekker, C., Quevillon, L. E., Smith, P. B., Fleming, K. R., Ghosh, D., Patterson, A. D., \& Hughes, D. P. (2014). Species-specific ant brain manipulation by a specialized fungal parasite. BMC Evolutionary Biology, 14(166), doi:10.1186/s12862-014-0166-3. doi:10.1186/s12862-014-0166-3

De Fine Licht, H. H., Jensen, A. B., \& Eilenberg, J. (2017). Comparative transcriptomics reveal host-specific nucleotide variation in entomophthoralean fungi. Molecular Ecology, 26(7), 2092-2110. doi:10.1111/mec. 13863

Ekseth, O. K., Kuiper, M., \& Mironov, V. (2014). OrthAgogue: An agile tool for the rapid prediction of orthology relations. Bioinformatics, 30(5), 734-736. doi:10.1093/bioinformatics/btt582

Evans, H. C., Elliot, S. L., \& Hughes, D. P. (2011). Hidden diversity behind the zombie-ant fungus ophiocordyceps unilateralis: Four new species described from carpenter ants in Minas Gerais, Brazil. PLoS ONE. doi:10.1371/journal.pone.0017024

Finn, R. D., Coggill, P., Eberhardt, R. Y., Eddy, S. R., Mistry, J., Mitchell, A. L. et al. (2016). The Pfam protein families database: Towards a more sustainable future. Nucleic Acids Research, 44(D1), D279D285. doi:10.1093/nar/gkv1344

Fisher, M. C., Henk, D. A., Briggs, C. J., Brownstein, J. S., Madoff, L. C., McCraw, S. L., \& Gurr, S. J. (2012). Emerging fungal threats to animal, plant and ecosystem health. Nature, 484(7393), 186-194. doi:10.1038/nature10947

Funaki, M., Katagiri, H., Inukai, K., Kikuchi, M., Asano, T. Structure and function of phosphatidylinositol3,4 kinase. Cellular Signalling, 12(3), 135-142. doi:10.1016/S0898-6568(99)00086-8

Gallo, A., Ferrara, M., \& Perrone, G. (2013). Phylogenetic study of polyketide synthases and nonribosomal peptide synthetases involved in the biosynthesis of mycotoxins. Toxins, 5(4), 717-742. doi:10.3390/toxins5040717

Gao, Q., Jin, K., Ying, S. H., Zhang, Y., Xiao, G., Shang, Y. et al. (2011). Genome sequencing and comparative transcriptomics of the model entomopathogenic fungi Metarhizium anisopliae and M. acridum. PLoS Genetics, 7(1), e1001264. doi:10.1371/journal.pgen.1001264

Ghanbarnia, K., Fudal, I., Larkan, N. J., Links, M. G., Balesdent, M. H., Profotova, B. et al. (2015). Rapid identification of the Leptosphaeria maculans avirulence gene AvrLm2 using an intraspecific comparative genomics approach. Molecular Plant Pathology, 16(7), 699-709. doi:10.1111/mpp.12228

Gillespie, J. P., Bailey, A. M., Cobb, B., \& Vilcinskas, A. (2000). Fungi as elicitors of insect immune responses. Archives of Insect Biochemistry and Physiology, 44(2), 49-68. doi:10.1002/15206327(200006)44:2<49::AID-ARCH1>3.0.CO;2-F

Gladieux, P., Ropars, J., Badouin, H., Branca, A., Aguileta, G., De Vienne, D. M. et al. (2014). Fungal evolutionary genomics provides insight into the mechanisms of adaptive divergence in eukaryotes. Molecular Ecology, 23(4), 753-773. doi:10.1111/mec.12631

Haas, H. (2012). Iron - a key nexus in the virulence of Aspergillus fumigatus. Frontiers in Microbiology, 3(28), 1-10. doi:10.3389/fmicb.2012.00028

Hartmann, F. E., Rodríguez de la Vega, R. C., Brandenburg, J. T., Carpentier, F., Giraud, T. (2018) Speciesspecificity and phylogeographic structure of gene presence-absence polymorphism in castrating anther-smut fungi. $G B E$, in press.

Herrero, J., Muffato, M., Beal, K., Fitzgerald, S., Gordon, L., Pignatelli, M. et al. (2016). Ensembl 
comparative genomics resources. Database: The Journal of Biological Databases and Curation,

Hu, X., Xiao, G., Zheng, P., Shang, Y., Su, Y., Zhang, X. et al. (2014). Trajectory and genomic determinants of fungal-pathogen speciation and host adaptation. Proceedings of the National Academy of Sciences of the United States of America, 111(47), 1-6. doi:10.1073/pnas.1412662111

Huang, J., Si, W., Deng, Q., Li, P., \& Yang, S. (2014). Rapid evolution of avirulence genes in rice blast fungus Magnaporthe oryzae. BMC Genetics, 15(45), 1-10. doi:10.1186/1471-2156-15-45

Hughes, D. P., Andersen, S. B., Hywel-Jones, N. L., Himaman, W., Billen, J., \& Boomsma, J. J. (2011). Behavioral mechanisms and morphological symptoms of zombie ants dying from fungal infection. BMC Ecology, 11(1), 13. doi:10.1186/1472-6785-11-13

Hughes, D. P., Araùjo, J. P. M., Loreto, R. G., Quevillon, L., de Bekker, C., Evans, H. C. (2016). From so simple a beginning: the evolution of behavioral manipulation by fungi. Advances in Genetics, 94, 437469. doi:10.1016/bs.adgen.2016.01.004

Ina, Y. (1996). Pattern of synonymous and nonsynonymous substitutions: An indicator of mechanisms of molecular evolution. Journal of Genetics, 75(1), 91. doi:10.1007/BF02931754

Jarrold, S. L., Moore, D., Potter, U., \& Charnley, A. K. (2007). The contribution of surface waxes to prepenetration growth of an entomopathogenic fungus on host cuticle. Mycological Research, 111(2), 240-249. doi:10.1016/j.mycres.2006.10.007

Jones, P., Binns, D., Chang, H. Y., Fraser, M., Li, W., McAnulla, C. et al. (2014). InterProScan 5: Genomescale protein function classification. Bioinformatics, 30(9), 1236-1240. doi:10.1093/bioinformatics/btu031

Juárez-Vázquez, A. L., Edirisinghe, J. N., Verduzco-Castro, E. A., Michalska, K., Wu, C., Noda-García, L. et al. (2017). Evolution of substrate specificity in a retained enzyme driven by gene loss. eLife, 6, e22679. doi:10.7554/eLife.22679

Kanehisa, M., Sato, Y., Kawashima, M., Furumichi, M., \& Tanabe, M. (2016). KEGG as a reference resource for gene and protein annotation. Nucleic Acids Research, 44(D1), D457-D462. doi:10.1093/nar/gkv1070

Keller, O., Kollmar, M., Stanke, M., \& Waack, S. (2011). A novel hybrid gene prediction method employing protein multiple sequence alignments. Bioinformatics, 27(6), 757-763. doi:10.1093/bioinformatics/btr010

Khaldi, N., Seifuddin, F. T., Turner, G., Haft, D., Nierman, W. C., Wolfe, K. H., Fedorova, N. D. (2010). SMURF: genomic mapping of fungal secondary metabolite clusters. Fungal Genetics and Biology, 47(9), 736-741. doi:10.1016/j.fgb.2010.06.003.

Kim, K.T., Jeon, J., Choi, J., Cheong, K., Song, H., Choi, G. et al. (2016) Kingdom-wide analysis of fungal small secreted proteins (SSPs) reveals their potential role in host association. Frontiers in Plant Science, 7, 186. doi: 10.3389/fpls.2016.00186.

Kimura, M. (1983). The neutral theory of molecular evolution. Cambridge University Press.

Kobmoo, N., Mongkolsamrit, S., Tasanathai, K., Thanakitpipattana, D., \& Luangsa-Ard, J. J. (2012). Molecular phylogenies reveal host-specific divergence of Ophiocordyceps unilateralis sensu lato following its host ants. Molecular Ecology, 21(12), 3022-3031. doi:10.1111/j.1365- 
Kobmoo, N., Mongkolsamrit, S., Wutikhun, T., Tasanathai, K., Khonsanit, A., Thanakitpipattana, D., \& Luangsa-Ard, J. J. (2015). New species of Ophiocordyceps unilateralis, an ubiquitous pathogen of ants from Thailand. Fungal Biology, 119(1), 44-52. doi:10.1016/j.funbio.2014.10.008

Korf, I. (2004). Gene finding in novel genomes. BMC Bioinformatics, 5, 59. doi:10.1186/1471-2105-5-59

Kurtz, J., Schulenburg, H., \& Reusch, T. B. (2016). Host-parasite coevolution-Rapid reciprocal adaptation and its genetic basis. Zoology, 119, 241-243. doi:10.1016/j.zool.2016.06.011

Langner, T., \& Göhre, V. (2016). Fungal chitinases: function, regulation, and potential roles in plant/pathogen interactions. Current Genetics, 62(2), 243-254. doi:10.1007/s00294-015-0530-x

Lee K.-T., So Y.-S., Yang D. et al. (2016). Systematic functional analysis of kinases in the fungal pathogen

Lespinet, O., Wolf, Y. I., Koonin, E. V., \& Aravind, L. (2002). The role of lineage-specific gene family expansion in the evolution of eukaryotes. Genome Research, 12(7), 1048-1059. doi:10.1101/gr.174302

Lomsadze, A., Ter-Hovhannisyan, V., Chernoff, Y. O., \& Borodovsky, M. (2005). Gene identification in novel eukaryotic genomes by self-training algorithm. Nucleic Acids Research, 33(20), 6494-6506. doi:10.1093/nar/gki937

Luo, Z., Qin, Y., Pei, Y., Keyhani, N. O. (2014). Ablation of the creA regulator results in amino acid toxicity, temperature sensitivity, pleiotropic effects on cellular development and loss of virulence in the filamentous fungus Beauveria bassiana. Environmental Microbiology, 16(4), 1122-1136. doi:10.1111/1462-2920.12352

Möller, M., \& Stukenbrock, E. H. (2017). Evolution and genome architecture in fungal plant pathogens. Nature Reviews Microbiology. doi:10.1038/nrmicro.2017.76

Mondal, S., Baksi, S., Koris, A., \& Vatai, G. (2016). Journey of enzymes in entomopathogenic fungi. Pacific Science Review A: Natural Science and Engineering, 18(2), 85-99. doi:10.1016/j.psra.2016.10.001

Murrell, B., Weaver, S., Smith, M. D., Wertheim, J. O., Murrell, S., Aylward, A. et al. (2015). Gene-wide identification of episodic selection. Molecular Biology and Evolution, 32(5), 1365-1371. doi:10.1093/molbev/msv035

Nielsen, R., \& Yang, Z. (1998). Likelihood models for detecting positively selected amino acid sites and applications to the HIV-1 envelope gene. Genetics, 148, 929-936.

Ogata, H., Goto, S., Sato, K., Fujibuchi, W., Bono, H., \& Kanehisa, M. (1999). KEGG: Kyoto encyclopedia of genes and genomes. Nucleic Acids Research, 28(1), 27-30. doi:10.1093/nar/27.1.29

Ohno, S. (1970). Evolution by Gene Duplication. Springer-Verlag.

Ortiz-Urquiza, A., \& Keyhani, N. O. (2013). Action on the surface: Entomopathogenic fungi versus the insect cuticle. Insects, 4(3), 357-374. doi:10.3390/insects4030357

Ortiz-Urquiza, A., Riveiro-Miranda, L., Santiago-Álvarez, C., \& Quesada-Moraga, E. (2010). Insect-toxic secreted proteins and virulence of the entomopathogenic fungus Beauveria bassiana. Journal of Invertebrate Pathology, 105(3), 270-8. doi:10.1016/j.jip.2010.07.003 
802

803

804

805

806

807

808

809

810

811

812

813

814

815

816

817

818

819

820

821

822

823

824

825

826

827

828

829

830

831

832

833

834

835

836

837

838

839

840

841

Parra, G., Bradnam, K., \& Korf, I. (2007). CEGMA: A pipeline to accurately annotate core genes in eukaryotic genomes. Bioinformatics, 23(9), 1061-1067. doi:10.1093/bioinformatics/btm071

Pattemore, J. A., Hane, J. K., Williams, A. H., Wilson, B. Al, Stodart, B. J., \& Ash, G. J. (2014). The genome sequence of the biocontrol fungus Metarhizium anisopliae and comparative genomics of Metarhizium species, BMC Genomics, 15(660), 1-15. doi:10.1186/1471-2164-15-660

Pedrini, N., Ortiz-Urquiza, A., Huarte-Bonnet, C., Zhang, S., \& Keyhani, N. O. (2013). Targeting of insect epicuticular lipids by the entomopathogenic fungus Beauveria bassiana: Hydrocarbon oxidation within the context of a host-pathogen interaction. Frontiers in Microbiology, 4(24), 1-18. doi:10.3389/fmicb.2013.00024

Petersen, T. N., Brunak, S., von Heijne, G., \& Nielsen, H. (2011). SignalP 4.0: discriminating signal peptides from transmembrane regions. Nature Methods, 8(10), 785-786. doi:10.1038/nmeth.1701

Plissonneau, C., Benevenuto, J., Mohd-Assaad, N., Fouché, S., Hartmann, F. E., Croll, D. (2017). Using Population and Comparative Genomics to Understand the Genetic Basis of Effector-Driven Fungal Pathogen Evolution. Frontiers in Plant Science, 8, 119. doi:10.3389/fpls.2017.00119

Pontoppidan, M. B., Himaman, W., Hywel-Jones, N. L., Boomsma, J. J., \& Hughes, D. P. (2009). Graveyards on the move: The spatio-temporal distribution of dead ophiocordyceps-infected ants. PLoS ONE, 4(3), e4835. doi:10.1371/journal.pone.0004835

Poppe, S., Dorsheimer, L., Happel, P., Stukenbrock, E. H. (2015). Rapidly Evolving Genes Are Key Players in Host Specialization and Virulence of the Fungal Wheat Pathogen Zymoseptoria tritici (Mycosphaerella graminicola). PLoS Pathogens, 11(7), e1005055.

Rafiqi, M., Ellis, J. G., Ludowici, V. A., Hardham, A. R., \& Dodds, P. N. (2012). Challenges and progress towards understanding the role of effectors in plant-fungal interactions. Current Opinion in Plant Biology, 15(4), 477-482. doi:10.1016/j.pbi.2012.05.003

Roman D., Dancis A., Anderson G., Klausner R. (1993). The fission yeast ferric reductase gene frp1+ is required for ferric uptake and encodes a protein that is homologous to the gp91-phox subunit of the human NADPH phagocyte oxidoreductase. Molecular and Cellular Biology, 13(7), 4342-4350. doi: 10.1128/MCB.13.7.4342

Ranwez, V., Harispe, S., Delsuc, F., \& Douzery, E. J. P. (2011). MACSE: Multiple alignment of coding SEquences accounting for frameshifts and stop codons. PLoS ONE, 6(9), e22594. doi:10.1371/journal.pone.0022594

Rawlings, N. D., Barrett, A. J., Finn, R. (2016). Twenty years of the MEROPS database of proteolytic enzymes, their substrates and inhibitors. Nucleic Acids Research, 44(D1), D343-D350. doi: 10.1093/nar/gkv1118

Rouxel, T., \& Balesdent, M. H. (2017). Life, death and rebirth of avirulence effectors in a fungal pathogen of Brassica crops, Leptosphaeria maculans. New Phytologist, 214(2), 526-532. doi:10.1111/nph.14411

Sakolrak, B., Blatrix, R., Sangwanit, U., Arnamnart, N., Kobmoo, N. (2018). Experimental infection of the ant Polyrhachis furcata with Ophiocordyceps reveals specificity of behavioral manipulation. Fungal Ecology, 33, 122-124. doi: 10.1016/j.funeco.2018.03.001

Schirrmann, M. K., Zoller, S., Croll, D., Stukenbrock, E. H., Leuchtman, A., Fior, S. (2018). Genomewide 
signatures of selection in Epichloë reveal candidate genes for host specialization. Molecular Ecology, 2018 (00), 1-17. doi:10.1111/mec.14585

Schrank, A., \& Vainstein, M. H. (2010). Metarhizium anisopliae enzymes and toxins. Toxicon, 56(7), 12671274. doi:10.1016/j.toxicon.2010.03.008

Sexton, A. C., \& Howlett, B. J. (2006). Parallels in fungal pathogenesis on plant and animal hosts. Eukaryotic Cell, 5(12), 1941-1949. doi:10.1128/EC.00277-06

Shah, F. A., Wang, C. S., \& Butt, T. M. (2005). Nutrition influences growth and virulence of the insectpathogenic fungus Metarhizium anisopliae. FEMS Microbiology Letters, 251(2), 259-266. doi:10.1016/j.femsle.2005.08.010

Shang, Y., Xiao, G., Zheng, P., Cen, K., Zhan, S., \& Wang, C. (2016). Divergent and Convergent Evolution of Fungal Pathogenicity. Genome Biology and Evolution, 8(5), 1374-1387. doi:10.1093/gbe/evw082

Singh, A., \& Poeta, M. D. (2011). Lipid signalling in pathogenic fungi. Cellular Microbiology, 13(2), 177 185. doi:10.1111/j.1462-5822.2010.01550.x

Singh, D., Son, S. Y., \& Lee, C. H. (2016). Perplexing metabolomes in fungal-insect trophic interactions: A Terra incognita of mycobiocontrol mechanisms. Frontiers in Microbiology, 7, 1678. doi:10.3389/fmicb.2016.01678

Stamatakis, A. (2014). RAxML version 8: a tool for phylogenetic analysis and post-analysis of large phylogenies. Bioinformatics, 30(9), 1312-1313. doi:10.1093/bioinformatics/bt1446

Stukenbrock, E. H., Bataillon, T., Dutheil, J. Y., Hansen, T. T., Li, R., Zala, M. et al. (2011). The making of a new pathogen: Insights from comparative population genomics of the domesticated wheat pathogen Mycosphaerella graminicola and its wild sister species. Genome Research, 21(12), 21572166. doi:10.1101/gr.118851.110

Sutak R., Lesuisse E., Tacherzy J., Richardson D. (2008) Crusade for iron: iron uptake in unicellular eukaryotes and its significance for virulence. Trends in Microbiology, 16(6), 261-268. doi: 10.1016/j.tim.2008.03.005

Swanson, W. J., Nielsen, R., \& Yang, Q. (2003). Pervasive adaptive evolution in mammalian fertilization $\begin{array}{lllll}\text { proteins. Molecular } & \text { Biology }\end{array}$ doi:10.1093/oxfordjournals.molbev.a004233

Thompson, S. N. (2003). Trehalose - The Insect "Blood" Sugar. Advances in Insect Physiology, 31, 205285. doi:10.1016/S0065-2806(03)31004-5

Wang, C., \& Feng, M. G. (2014). Advances in fundamental and applied studies in China of fungal biocontrol agents for use against arthropod pests. Biological Control, 68(1), 129-135. doi:10.1016/j.biocontrol.2013.06.017

Wang, C., \& St. Leger, R. J. (2005). Developmental and Transcriptional Responses to Host and Nonhost Cuticles by the Specific Locust Pathogen Metarhizium anisopliae var. acridum. Eukaryotic Cell, 4(5), 937-947. doi:10.1128/EC.4.5.937-947.2005

Wang, C., \& Wang, S. (2017). Insect Pathogenic Fungi: Genomics, Molecular Interactions, and Genetic Improvements. Annu. Rev. Entomol, 62, 73-90. doi:10.1146/annurev-ento-031616-035509

Wang, G., Liu, Z., Lin, R., Li, E., Mao, Z., Ling, J. et al. (2016). Biosynthesis of Antibiotic Leucinostatins 
881

882

883

884

885

886

887

888

889

890

891

892

893

894

895

896

897

898

899

900

901

902

903

904

905

906

907

908

909

910

911

912

913

914

915

916

917

918

919

920

in Bio-control Fungus Purpureocillium lilacinum and Their Inhibition on Phytophthora Revealed by Genome Mining. PLoS Pathogens, 12(7), e1005685. doi:10.1371/journal.ppat.1005685

Wang S, Fang W, Wang C, St. Leger RJ (2011) Insertion of an Esterase Gene into a Specific Locust Pathogen (Metarhizium acridum) Enables It to Infect Caterpillars. PLoS Pathog 7(6): e1002097. doi:10.1371/journal.ppat.1002097

Wang, S., Leclerque, A., Pava-Ripoll, M., Fang, W., \& St. Leger, R. J. (2009). Comparative genomics using microarrays reveals divergence and loss of virulence-associated genes in host-specific strains of the insect pathogen metarhizium anisopliae. Eukaryotic Cell, 8(6), 888-898. doi:10.1128/EC.00058-09

Wichadakul, D., Kobmoo, N., Ingsriswang, S., Tangphatsornruang, S., Chantasingh, D., Luangsa-Ard, J. J., \& Eurwilaichitr, L. (2015). Insights from the genome of Ophiocordyceps polyrhachis-furcata to pathogenicity and host specificity in insect fungi. BMC Genomics, 16, 881. doi:10.1186/s12864-0152101-4

Wicker, T., Oberhaensli, S., Parlange, F., Buchmann, J. P., Shatalina, M., Roffler, S. et al. (2013). The wheat powdery mildew genome shows the unique evolution of an obligate biotroph. Nature Genetics, 45(9), 1092-1096. doi:10.1038/ng.2704

Wiygul, G., \& Sikorowski, P. P. (1986). The effect of staphylococcal enterotoxin B on pheromone production in fat bodies isolated from male boll weevils. Journal of Invertebrate Pathology, 47(1), $116-119$.

Wiygul, G., \& Sikorowski, P. P. (1991). The effect of a heat-stable enterotoxin isolated from Escherichia coli on pheromone production in fat bodies isolated from male boll weevils. Entomologia Experimentalis et Applicata, 60(3), 305-308. doi:10.1111/j.1570-7458.1991.tb01551.x

Wongsa, P., Tasanatai, K., Watts, P., \& Hywel-Jones, N. (2005). Isolation and in vitro cultivation of the insect pathogenic fungus Cordyceps unilateralis. Mycological Research, 109(8), 936-940. doi:10.1017/S0953756205003321

Xia, E.-H., Yang, D.-R., Jiang, J.-J., Zhang, Q.-J., Liu, Y., Liu, Y.-L. et al. (2017). The caterpillar fungus, Ophiocordyceps sinensis, genome provides insights into highland adaptation of fungal pathogenicity. Scientific Reports, 7, 1806. doi:10.1038/s41598-017-01869-z

Xiao, G., Ying, S., Zheng, P., Wang, Z.-L., Zhang, S., Xie, X.-Q. et al. (2012). Genomic perspectives on the evolution of fungal entomopathogenicity in Beauveria bassiana. Scientific Reports, 2, 483.

Yang, Z. (1998). Likelihood ratio tests for detecting positive selection and application to primate lysozyme evolution. Mol Biol Evol, 15(5), 568-573. doi:10.1093/oxfordjournals.molbev.a025957

Yang, Z. (2007). PAML 4: Phylogenetic analysis by maximum likelihood. Molecular Biology and Evolution, 24(8), 1586-1591. doi:10.1093/molbev/msm088

Yang, Z., \& Nielsen, R. (1998). Synonymous and Nonsynonymous Rate Variation in Nuclear Genes of Mammals. Journal of Molecular Evolution, 46, 409-418.

Yang, Z., \& Nielsen, R. (2000). Estimating synonymous and nonsynonymous substitution rates under realistic evolutionary models. Molecular Biology and Evolution, 17(1), 32-43. doi:10.1093/oxfordjournals.molbev.a026236

Yang, Z., Nielsen, R., Goldman, N., \& Krabbe Pedersen, A.-M. (2000). Codon-Substitution Models for Heterogeneous Selection Pressure at Amino Acid Sites. Genetics, 155, 431-449. 
921 Yang, Z., Wong, W. S. W., \& Nielsen, R. (2005). Bayes empirical Bayes inference of amino acid sites under positive selection. Molecular Biology and Evolution, 22(4), 1107-1118. doi:10.1093/molbev/msi097

923 Yin, Y., Mao, X., Yang, J., Chen, X., Mao, F., Xu, Y. (2012). dbCAN: a web resource for automated carbohydrate-active enzyme annotation. Nucleic Acids Research, 40(W1), 445-451.

Zhang, J., Zhang, Y.-P., \& Rosenberg, H. F. (2002). Adaptive evolution of a duplicated pancreatic ribonuclease gene in a leaf-eating monkey. Nature Genetics, 30, 411-415. doi:10.1038/ng852

927 Zheng, P., Xia, Y., Xiao, G., Xiong, C., Hu, X., Zhang, S. et al. (2011). Genome sequence of the insect pathogenic fungus Cordyceps militaris, a valued traditional chinese medicine. BMC Genome Biology, 12(11), R116.

Zhou, K., Huang, B., Zou, M., Lu, D., He, S., \& Wang, G. (2015). Genome-wide identification of lineagespecific genes within Caenorhabditis elegans. Genomics, 106(4), 242-248. doi:10.1016/j.ygeno.2015.07.002

\section{Data Accessibility}

935 The de-novo assemblies of Ophiocordyceps camponoti-leonardi (NCBI Biosample

936 SAMN07662903) and O. camponoti-saundersi (NCBI Biosample SAMN07662932) have been

937 deposited with the NCBI as whole-genome shotgun (WGS) projects with accession numbers

938 PDHP00000000 and PDHQ00000000, respectively. The O. polyrhachis-furcata genome was

939 updated based on the improved assembly from this study (LKCN02000000).

940

941 Author Contributions

942 N.K., J.J.L. and T.G. designed the study. N.K. and N.A. conducted sampling and DNA extraction.

943 N.K., D.W. and RCRSLV analyzed sequencing and comparative genomic data. N.K. and T.G.

944 wrote the manuscript, with contributions from all the authors.

945

946 Supporting information 
947 Table S1. Orthologous clusters of genes encoding heat-labile enterotoxins in species of the

948 Hypocreales.

949 Table S2. List of genes unique to one of the three complexes: Ophiocordyceps unilateralis, $O$.

950 australis, O. subramanianii.

951 Table S3. List of species-specific genes for the Ophiocordyceps unilateralis complex.

952 Table S4. List of species-specific genes for the Ophiocordyceps australis complex.

953 Table S5. List of the 5\% of genes with the highest non-synonymous-to-synonymous substitution

954 rate ratios $(\mathrm{dN} / \mathrm{dS})$ values, with functional annotations.

955 Table S6. Complete list of genes with significant likelihood ratio tests (LRTs) after false

956 discovery rate (fdr) correction.

957 Table S7. Results of likelihood ratio tests (LRTs) for categories of genes thought to be involved

958 in adaptation.

959 Table S8. Results of likelihood ratio tests (LRTs) for putative neuromodulator genes (after De

960 Bekker et al. 2017).

961

962

$963 \quad$ Figure captions

964 Figure 1. Inference of orthologous groups: Venn diagram showing the number of orthologous

965 groups common to and specific to species complexes and species a. between the three ant-infecting

966 Ophiocordyceps species complexes used in this study; b. between the species in the O. unilateralis

967 complex $(\mathrm{OPF}=$ O. polyrhachis-furcata, $\mathrm{OCL}=$ O. camponoti-leonardi, $\mathrm{OCS}=$ O. camponoti- 
968 saundersi, $\mathrm{OKi}=$ O. kimflemingiae, $\mathrm{OCR}=$ O. camponoti-rufipedis $), \mathrm{b}$. between the species in the

969 O. australis complex $(\mathrm{OAG}=$ O. australis from Ghana, $\mathrm{OAB}=$ O. australis from Brazil $)$.

970

971 Figure 2. The best maximum-likelihood tree based on 4,014 single-copy orthologous groups with

972 bootstrap supports. The horizontal scale bar represents the branch length based on substitution

973 rates.

974

975 Figure 3. Distribution of pairwise non-synonymous-to-synonymous substitution ratios (dN/dS) for

976 the genes in all orthologous groups in the Ophiocordyceps unilateralis s.l. species complex. (a)

977 Whole-genome dN/dS distributions, (b) Boxplots of pairwise dN/dS values for the whole genome

978 (small secreted protein-coding genes or SSPs, in blue, versus non-SSPs, in red) and between

979 different categories of genes suspected a priori to be involved in pathogenesis and virulence, i.e.,

980 with the putative functions of enterotoxins, core proteins of secondary metabolism (SM), lipases,

981 proteases (including subtilisin-like, trypsin and aspartyl proteases) and trehalases. The dotted line

982 represents the mean $\mathrm{dN} / \mathrm{dS}$ value for the whole genome (0.145).

983

984 Figure 4. Percentages of genes in various functional categories for which likelihood ratio tests

985 (LRTs) for positive selection (M7 vs. M8 and M8a vs. M8) yielded significant results (false

986 discovery rate-corrected $p$-value $<0.05)$. Proteases $=$ subtilisin, trypsin and aspartyl proteases, SM

$987=$ core genes of secondary metabolites. The total number of genes in each category is indicated 988 above the bars.

989 
990 Figure 5. Homology of putative secondary metabolic gene clusters (SMGCs) with the core gene 991 under positive selection according to log likelihood ratio tests (M7 vs. M8 models and M8a vs. M8

992 models). The dashed lines indicate orthology between the putative polyketide synthase (PKS)-like

993 core gene. The phylogenetic tree was inferred from Jaccard similarity indices between alignments

994 of common gene domains within families. OCS = Ophiocordycyceps camponoti-saundersi, OCL

$995=$ O. camponoti-leonardi, $\mathrm{OPF}=O$. polyrhachis-furcata, $\mathrm{OKi}=O$. kimflemingiae, $\mathrm{OCR}=O$.

996 camponoti-rufipedis, $\mathrm{OAG}=$ O. australis from $\mathrm{Ghana}, \mathrm{OAB}=$ O. australis from Brazil, $\mathrm{OSS}=O$.

997 subramanianii.

998

999 Figure 6. The best RAxML tree based on the GTRCAT model for the orthologous group 1000 ORTHAgEnt13 of putative heat-labile enterotoxins in entomopathogenic and nematode-killing 1001 fungi of the order Hypocreales. The numbers above the nodes are bootstrap supports. The numbers 1002 below the branches are the ratios of non-synonymous-to-synonymous substitution rates (dN/dS). 
(a) O. unilateralis
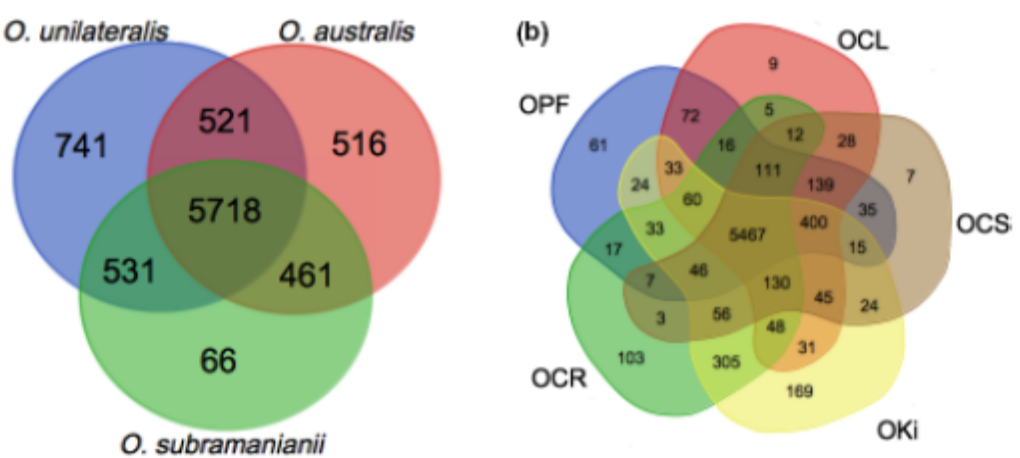

(c) OAG

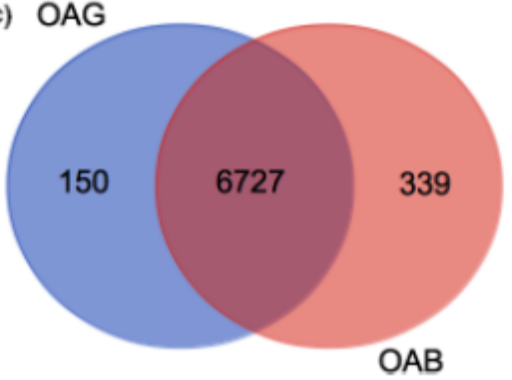

FIGURE 1 Inference of orthologous groups: Venn diagram showing the number of orthologous groups common to and specific to species complexes and species a. between the three ant-infecting Ophiocordyceps species complexes used in this study; (b) between the species in the O. unilateralis complex

(OPF $=0$. polyrhachis-furcata, $\mathrm{OCL}=0$. camponoti-leonardi, $\mathrm{OCS}=\mathrm{O}$. camponoti-saundersi, $\mathrm{OKi}=\mathrm{O}$. kimflemingiae, $\mathrm{OCR}=0$. camponoti-rufipedis), (c) between the species in the $O$. australis complex $(O A G=0$. australis from Ghana, $\mathrm{OAB}=0$. australis from Brazil) 
FIGURE 2 The best maximumlikelihood tree based on 4,014 single-copy orthologous groups with bootstrap supports. The horizontal scale bar represents the branch length based on substitution rates

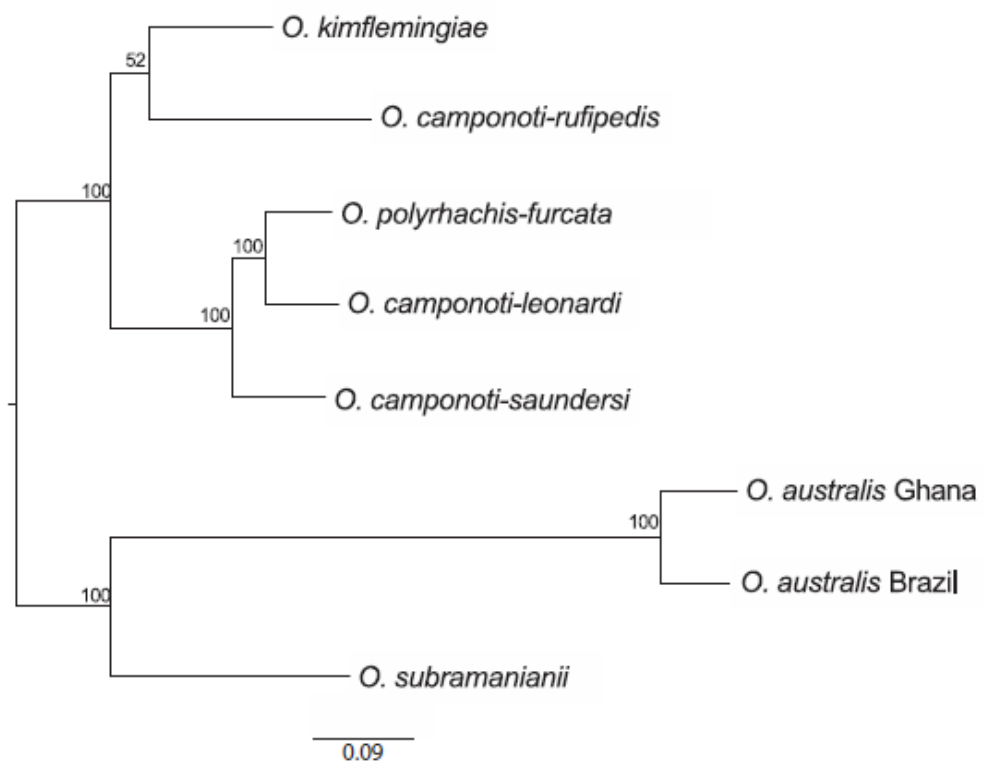


(a)

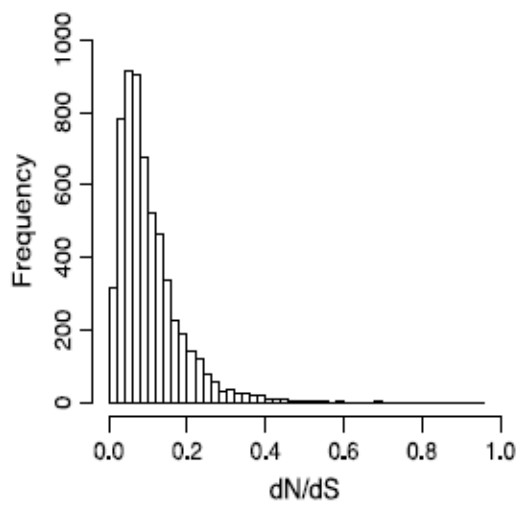

(b)

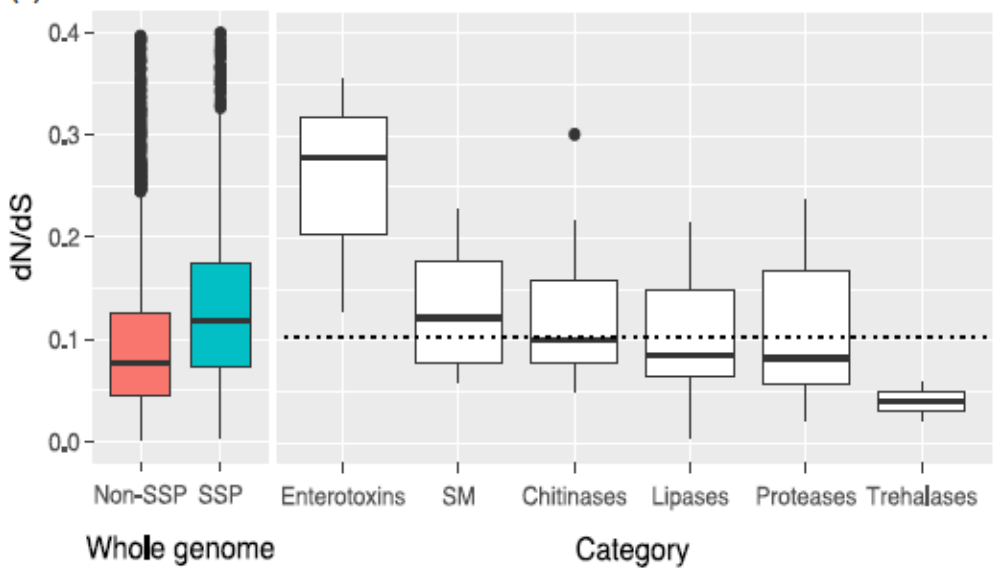

FIGURE 3 Distribution of pairwise nonsynonymous-to-synonymous substitution ratios (dN/dS) for the genes in all single-copy orthologous groups with at least four species of ant-infecting Ophiocordyceps represented. (a) Whole-genome dN/dS distributions, (b) Boxplots of pairwise $\mathrm{dN} / \mathrm{dS}$ values for the whole genome (small secreted protein-coding genes or SSPs, in blue, vs. non-SSPs, in red) and between different categories of genes suspected a priori to be involved in pathogenesis and virulence, that is, with the putative functions of enterotoxins, core proteins of secondary metabolism (SM), lipases, proteases (including subtilisin-like, trypsin and aspartyl proteases) and trehalases. The dotted line represents the mean $\mathrm{dN} / \mathrm{dS}$ value for the whole genome (0.145) 
FIGURE 4 Percentages of genes in various functional categories for which likelihood ratio tests (LRTs) for positive selection (M7 vs. M8 and M8a vs. M8) yielded significant results (false-discovery rate-corrected $p$-value $<0.05$ ).

Proteases = subtilisin, trypsin and aspartyl proteases, $\mathrm{SM}=$ core genes of secondary metabolites. The total number of genes in each category is indicated above the bars

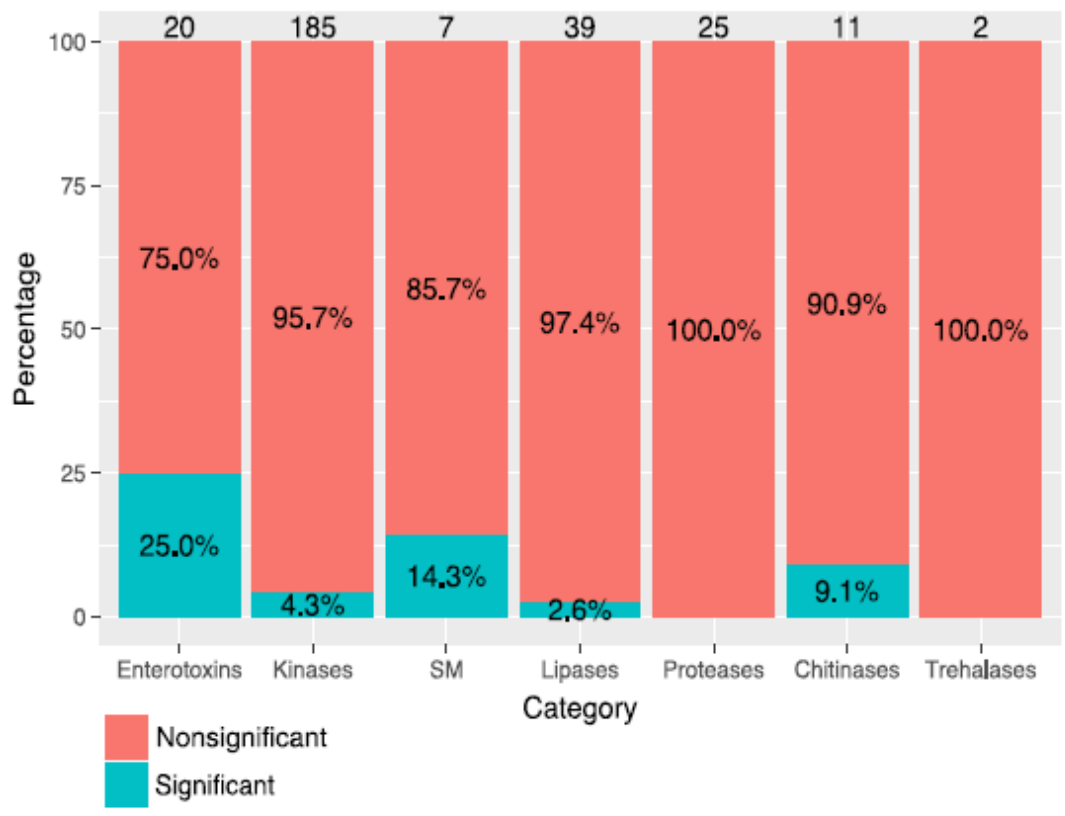

1010

1011 


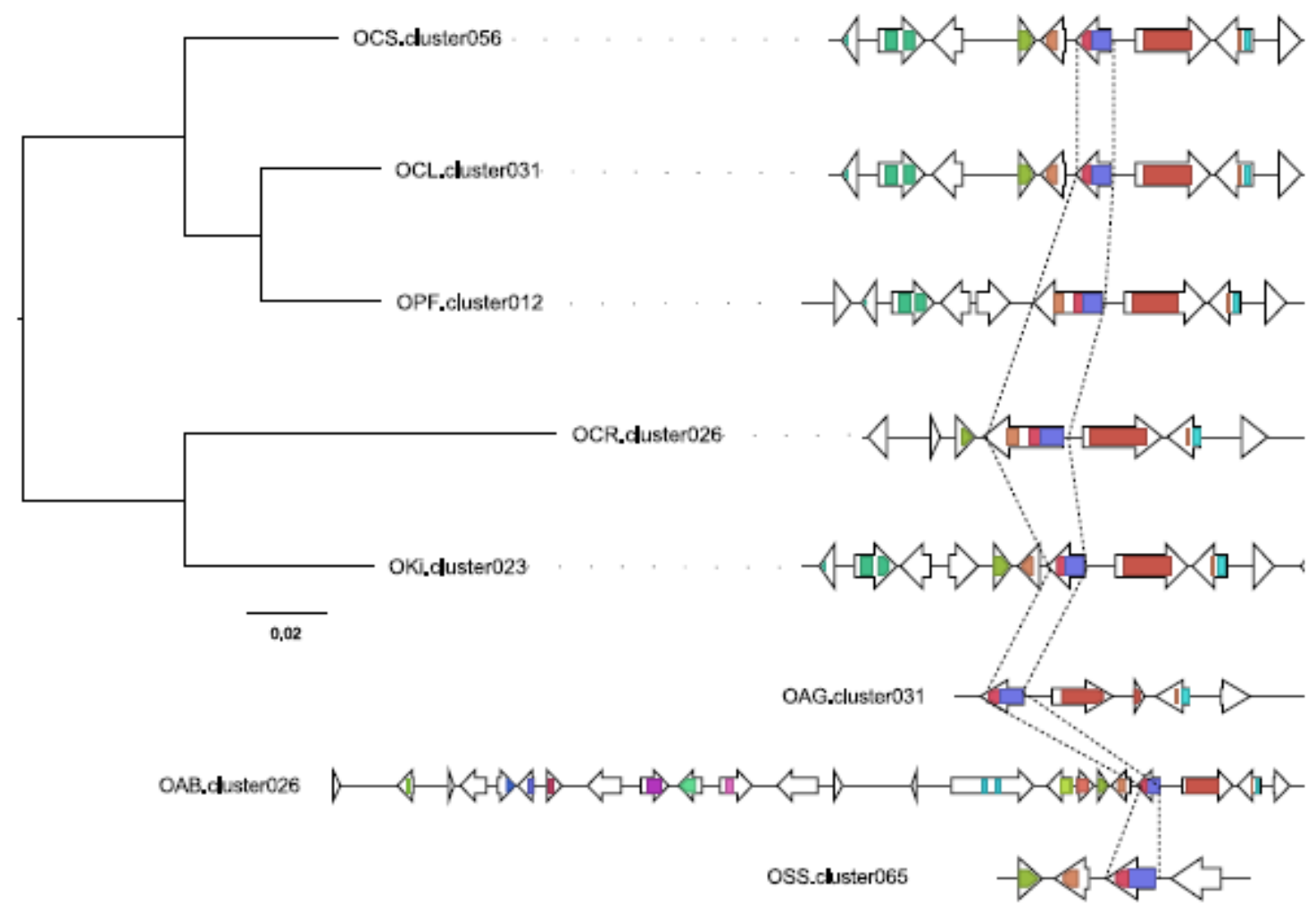

FI GURE 5 Homology of putative secondary metabolic gene clusters (SMGCS) with the core gene under positive selection according to loglikelihood ratio tests (M7 vs. M8 models and MBa vs MB models). The dashed lines indicate orthology between the putative polyketide synthase (PKS)-like core gene. The phylogenetic tree was inferred from Jaccard similarity indices between alignments of common gene domains within families. OCS - Ophiocardyceps camponoti-saundersi, $\mathrm{OCL}=0$. camponoti-leonardi, OPF $=0$. pdyrhachis-furcata,

1012

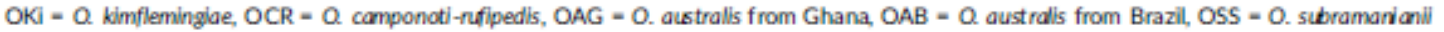




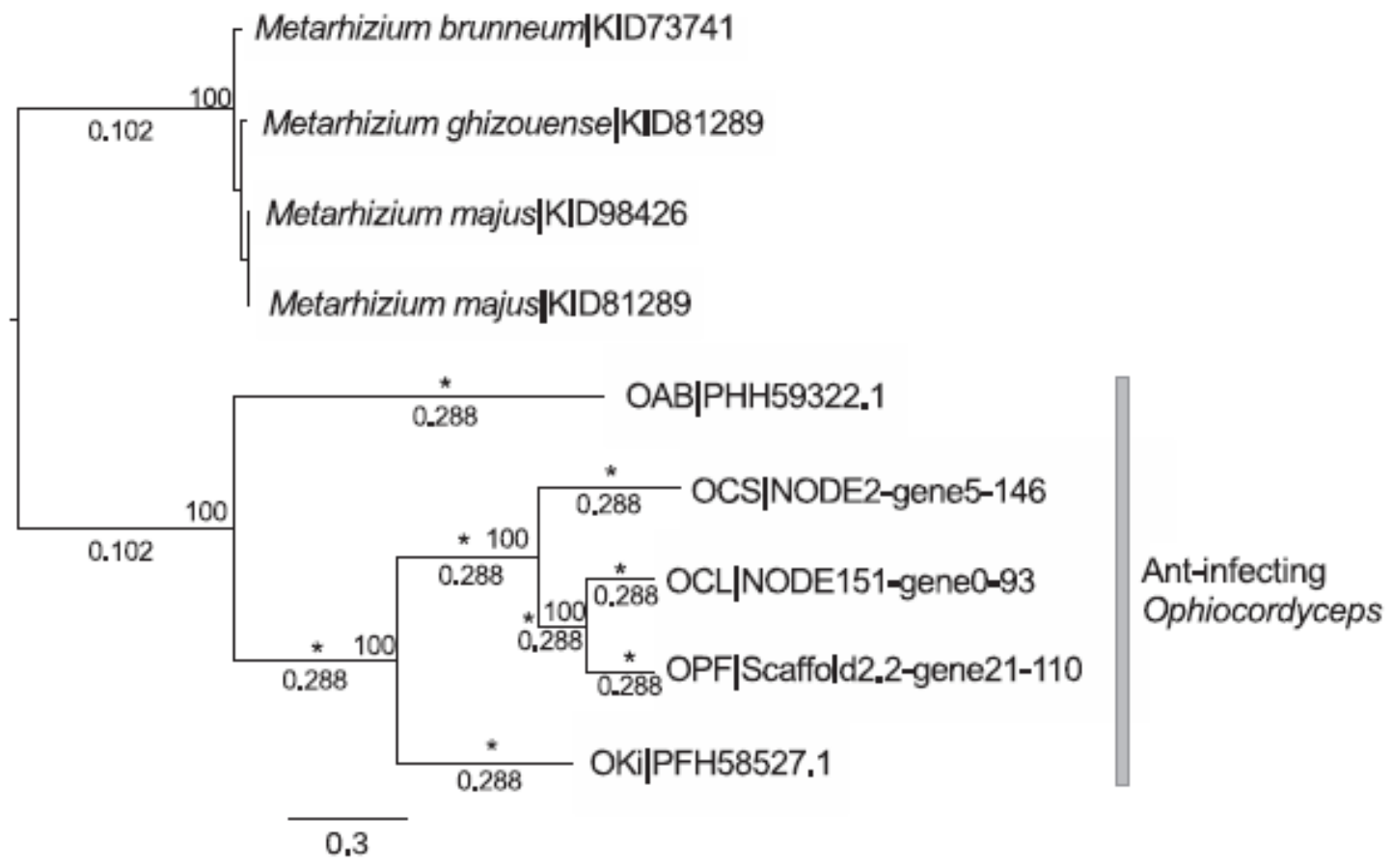

FIGURE 6 The best RAXML tree based on the GTRCAT model for the orthologous group ORTHAgEnt 13 of putative heat-labile enterotoxins in entomopathogenic and nematode-killing fungi of the order Hypocreales. The numbers above the nodes are bootstrap supports. 1014 The numbers below the branches are the ratios of nonsynonymous-to-synomymous substitution rates (dN/dS) 